\title{
Efficacy of Intermittent or Continuous Very Low-Energy Diets in Overweight and Obese Individuals with Type 2 Diabetes Mellitus: A Systematic Review and Meta-Analyses
}

\author{
Yi Shan Huang $\mathbb{D}^{1}{ }^{1}$ Qiyan Zheng, ${ }^{1}$ Huisheng Yang, ${ }^{2}$ Xinwen $\mathrm{Fu}^{1}{ }^{1}$ Xueqin $\mathrm{Zhang},{ }^{1}$ \\ Chenhui Xia ${ }^{\mathbb{D}},{ }^{1}$ Zebing Zhu, ${ }^{1}$ Yu Ning Liu $\mathbb{D},{ }^{1,3}$ and Wei Jing Liu $\mathbb{D}^{1,4}$ \\ ${ }^{1}$ Renal Research Institution of Beijing University of Chinese Medicine, Dongzhimen Hospital Affiliated to Beijing University of \\ Chinese Medicine, Beijing 100700, China \\ ${ }^{2}$ Institute of Acupuncture and Moxibustion, China Academy of Chinese Medical Sciences, Beijing 100700, China \\ ${ }^{3}$ Department of Endocrinology Nephropathy, Dongzhimen Hospital Affiliated to Beijing University of Chinese Medicine, \\ Beijing 100700, China \\ ${ }^{4}$ Institute of Nephrology, Zhanjiang Key Laboratory of Prevention and Management of Chronic Kidney Disease, \\ Guangdong Medical University, Zhanjiang, Guangdong 524001, China
}

Correspondence should be addressed to Yu Ning Liu; yunin1946@sina.com and Wei Jing Liu; liuweijing-1977@hotmail.com

Received 8 September 2019; Accepted 7 January 2020; Published 29 January 2020

Guest Editor: Ruozhi Zhao

Copyright (C) 2020 Yi Shan Huang et al. This is an open access article distributed under the Creative Commons Attribution License, which permits unrestricted use, distribution, and reproduction in any medium, provided the original work is properly cited.

Objective. This study is aimed at investigating the efficacy of a very low-energy diet (VLED) in overweight and obese individuals with type 2 diabetes mellitus (T2DM). Methods. We thoroughly searched eight electronic resource databases of controlled studies concerning the efficacy and acceptability of intermittent or continuous VLEDs in patients with T2DM compared with other energy restriction interventions. Results. Eighteen studies (11 randomized and seven nonrandomized controlled trials) with 911 participants were included. The meta-analyses showed that compared with a low-energy diet (LED) and mild energy restriction (MER), VLED is superior in the reduction of body weight (mean difference (MD) M $\mathrm{D}_{\mathrm{LED}}=-2.77,95 \%$ confidence interval $(\mathrm{CI}) \mathrm{CI}_{\mathrm{LED}}=-4.81$ to $-0.72, P_{\mathrm{LED}}=0.008 ; \mathrm{MD}_{\mathrm{MER}}=-6.72,95 \% \mathrm{CI} \mathrm{MER}=-10.05$ to -3.39 , $\left.P_{\mathrm{MER}}<0.0001\right)$, blood glucose $\left(\mathrm{MD}_{\mathrm{LED}}=-1.18,95 \% \mathrm{CI}_{\mathrm{LED}}=-2.05\right.$ to $-0.30, P_{\mathrm{LED}}=0.008 ; \mathrm{MD}_{\mathrm{MER}}=-6.72,95 \% \mathrm{CI}_{\mathrm{MER}}=-10.05$ to $\left.-3.39, P_{\mathrm{MER}}<0.0001\right)$, and triglyceride $(\mathrm{TG})\left(\mathrm{MD}_{\mathrm{LED}}=-0.35,95 \% \mathrm{CI}_{\mathrm{LED}}=-0.58\right.$ to $-0.12, P_{\mathrm{LED}}=0.002 ; \mathrm{MD}_{\mathrm{MER}}=-0.55,95 \%$ $\mathrm{CI}_{\mathrm{MER}}=-0.93$ to $\left.-0.17, P_{\mathrm{MER}}=0.005\right)$ levels at the end of the intervention. After the follow-up (1-5 years), no obvious difference in weight loss $\left(\mathrm{MD}=-0.84,95 \% \mathrm{CI}=-3.01\right.$ to $\left.1.32, P=0.45, I^{2}=0 \%\right)$ and $\mathrm{TG}$ level $(\mathrm{MD}=-0.25,95 \% \mathrm{CI}=-0.55$ to $0.06, P=0.12$, $\left.I^{2}=0 \%\right)$ between VLEDs and LEDs was evident, but VLED is more effective in glycemic control $(\mathrm{MD}=-1.43,95 \% \mathrm{CI}=-2.65$ to $-0.20, P=0.02)$. Compared to bariatric surgery, VLEDs offered comparable effects on weight loss $(\mathrm{MD}=2.51,95 \% \mathrm{CI}=-9.52$ to $14.54, P=0.37)$, glycemic control $(\mathrm{MD}=0.37,95 \% \mathrm{CI}=-0.22$ to $0.96, P=0.22)$, $\mathrm{TG}(\mathrm{MD}=-0.3,95 \% \mathrm{CI}=-0.74$ to $0.17, P=0.7)$, and insulin resistance improvement $(\mathrm{MD}=-1,95 \% \mathrm{CI}=-2.7$ to $0.7, P=0.25)$. Conclusion. Dietary intervention through VLEDs is an effective therapy for rapid weight loss, glycemic control, and improved lipid metabolism in overweight and obese individuals with T2DM. Thus, VLEDs should be encouraged in overweight and obese individuals with T2DM who urgently need weight loss and are unsuitable or unwilling to undergo surgery. As all outcome indicators have low or extremely low quality after GRADE evaluation, further clinical trials that focus on the remission effect of VLEDs on T2DM are needed. 


\section{Introduction}

It is well known that obesity is a major risk factor for type 2 diabetes mellitus (T2DM) [1] and the majority of patients with T2DM are overweight or obese [2]. Obesity management is confirmed as an effective strategy in the prevention and remission of T2DM [3].

Multiple strategies including diet, physical activity, behavioural therapy, pharmacologic therapy, and bariatric surgery are recommended for obesity management [3]. In previous evidence-based clinical guidelines, dietary modification is recommended as a fundamental aspect of diabetes care, based on its benefits on glycemia and HbA1c levels [4]. Recently, several studies suggest that short-term and more extreme dietary energy restriction aiming on intensive weight loss can even reverse some cases of T2DM [5-7]. Very low-energy diet (VLED) has been confirmed as an effective and safe option for weight loss in obese individuals [8]. There is no standard definition of a VLED programme across different countries and continents [9-11]. However, a VLED is generally defined as a very low total energy intake $(\leq 800 \mathrm{kcal} /$ day $)[8,10]$. Recently, a growing body of studies focus on the efficacy and acceptability of VLEDs in patients with T2DM who are overweight or obese [12-14] and propose that VLEDs may be an underutilized therapy for patients with T2DM. Intermittent VLED is an alternative strategy of continuous VLEDs for T2DM, which typically involves periods of VLEDs interchanged by periods of ad libitum energy intake or mild energy restriction (MER, a slight diet intervention method which provides energy less than ad libitum energy intake but more than $1600 \mathrm{kcal} /$ day) $[15,16]$. The efficacy of both intermittent and continuous VLED should be considered.

A low-energy diet (LED) containing $800-1600 \mathrm{kcal} /$ day is also considered an option of clinical obesity management of patients with T2DM $[17,18]$, but the difference in efficacy and safety between VLEDs and LEDs is rarely discussed. Bariatric surgery is recommended for obese patients (body mass index (BMI), $35.0-39.9 \mathrm{~kg} / \mathrm{m}^{2}$ ) with $\mathrm{T} 2 \mathrm{DM}$ who did not achieve durable weight loss and improvement in comorbidities with reasonable surgical methods [3]. For example, Roux-en-Y gastric bypass (RYGB), as currently one of the most effective types of bariatric surgery, achieves energy limitation by reducing stomach capacity and reducing dietary intake. However, bariatric surgeries have more adverse effects and complications compared with energy restriction strategy. Moreover, VLEDs may produce a similar effect on glycemic control, $\beta$-cell function, and insulin sensitivity as bariatric surgeries. Thus, it is necessary to evaluate the efficacy of VLEDs compared with other methods of energy restriction in overweight and obese individuals with T2DM.

A previous systematic review among overweight and obesity individuals with T2DM found that VLED has benefits of weight loss and glycemic control [19]. However, the systematic review included a small number of participants, and the long-term effect of VLEDs is unclear. Another recently published systematic review found that VLED programmes in children and adolescents with obesity induce short- to medium-term weight loss and also demonstrated significant improvements in diabetic outcomes, such as HbAlc and glucose levels [10]. Recently, several clinical studies have been conducted to compare VLEDs with other energy restriction methods. Thus, it is necessary to investigate the efficacy of VLEDs in overweight and obese adult individuals with T2DM. Our systematic review and meta-analyses are aimed at clarifying the effect of VLEDs on weight loss, glycemic control, and blood lipid levels in overweight and obese individuals with T2DM and further exploring the longterm efficacy of VLEDs to provide more substantial evidence in the clinical application of VLEDs.

\section{Materials and Methods}

2.1. Search Strategy. We comprehensively searched PubMed, EMBASE, Cochrane Library, Web of Science, SINOMED, China National Knowledge Infrastructure, WanFang, and Chongqing VIP Information databases from inception until July 2019 for clinical trials investigating intermittent or continuous VLEDs for overweight and obese adults with T2DM. Additional studies were searched in the reference lists of all identified publications, including relevant meta-analyses and systematic reviews.

2.2. Inclusion Criteria. Published and unpublished randomized controlled trials (RCTs) and non-RCTs, which are clinical controlled studies evaluating the efficacy of intermittent or continuous VLEDs and qualitative studies exploring the acceptability of, barriers to, and facilitators of VLEDs, were considered for inclusion in this review.

We included clinical studies that satisfied the following criteria: (1) participants in the included studies were overweight or obese (mean $\mathrm{BMI} \geq 30 \mathrm{~kg} / \mathrm{m}^{2}$ or $\geq 10 \%$ above the ideal body weight based on the Metropolitan Life Insurance Company's tables); (2) adults (aged $\geq 18$ years) had T2DM in older studies using a different measure of obesity; (3) studies used intermittent or continuous VLEDs comprising $\leq 800 \mathrm{kcal} /$ day in at least one intervention arm; and (4) studies also had to include a control arm receiving other energy control methods, including LEDs (800-1600 kcal/day), bariatric surgery, and MER. We excluded clinical studies with the following features: (1) both the intervention and comparator arms received VLED treatment (except VLEDs after surgical treatment) and (2) the intervention is VLED combined with other weight loss drugs. If a study compared three or more arms, VLED arms were considered to be the intervention and other energy control methods the comparators.

The outcome indicators of this study include the following: (1) weight loss (kg), (2) fasting plasma glucose levels $(\mathrm{mmol} / \mathrm{l})$ and change in medication, (3) triglyceride (TG) level (mmol/l), (4) homeostatic model assessment of insulin resistance (HOMA-IR) level, (5) dropout, (6) side effects, and (7) rebound.

2.3. Data Extraction. Two reviewers (YS Huang and XW Fu) independently extracted data from original trial reports using a standardized form. Data extracted included study characteristics (first author, publication year, single center or multicenter, sample size, intervention and control, period of treatment, and follow-up duration), characteristics of 
patients (inclusion criteria, background treatments, mean age, proportion of men, baseline weight, and baseline glucose levels), reported outcomes (weight, fasting plasma glucose levels, and adverse events), and information on methodology. We contacted the study authors when we needed to obtain additional information that was unavailable in the online publications or supplementary materials.

2.4. Quality Assessment. Risk of bias of RCTs was assessed using the Cochrane Collaboration's tool [20]. We evaluated non-RCTs according to the Risk Of Bias In Nonrandomised Studies of Interventions (ROBINS-I) tool [21]. Two investigators independently completed the assessments, and discrepancies were discussed with a third party and resolved by consensus.

Additionally, the Grading of Recommendations, Assessment, Development, and Evaluation (GRADE) framework was used to assess the quality of evidence contributing to each network estimate, which characterizes the quality of a body of evidence on the basis of the study limitations, imprecision, inconsistency, indirectness, and publication bias for the primary outcomes [22].

2.5. Statistical Analyses. The data entry and analysis were conducted using Microsoft Excel 2016 and Review Manager software version 5.3, respectively. Risk ratio and standard mean difference with $95 \%$ confidence interval (CI) of the outcomes were calculated as effect measure. The $I^{2}$-statistic was calculated for heterogeneity, as a measure of the proportion of the overall variation that is attributable to between-study heterogeneity. A fixed-effects (FE) model was used if $I^{2}<$ $50 \%$; otherwise, the random-effects model was used.

To assess whether the results were influenced by study characteristics (effect modifiers), a subgroup analysis was conducted according to the study duration $(<12$ or $\geq 12$ months). Additionally, sensitivity analyses were performed before combining RCTs and non-RCTs in the metaanalyses to determine possible additional sources of heterogeneity and changes in effect sizes.

Publication bias was tested by visual inspection of the funnel plots. When few studies are included in the analysis, the power of the tests is too low; therefore, publication bias was only examined if $>10$ study comparisons were included in the analysis [23].

\section{Results}

3.1. Study Characteristics. The search identified 6746 studies, of which 2157 were duplicates. Then, 4589 titles and abstracts were screened, with 145 studies for full-text screening. Finally, 18 eligible studies (911 participants) [24-41] evaluated the effects of intermittent or continuous VLEDs on overweight or obese patients with T2DM compared with other energy control methods, and specifically, 7 studies (583 participants) [25-31] compared VLEDs with LEDs, 6 studies (204 participants) [36-41] with MER, and 5 studies (124 participants) [24, 32-35] with bariatric surgery. Particularly, among the five studies involving surgical treatment, four studies (Jackness et al. [24], Lips et al. [32], Plum et al. [33], and Steven et al. [35]) used gastric bypass and 1 study (Cinkajzlova et al. [34]) used a variety of surgical approaches, including gastric plication (10 participants), gastric banding (2 participants), and gastric bypass (1 participant). Seven of the 18 included studies were non-RCTs. All of them were observational studies, four of them (Jackness et al. [24], Lips et al. [32], Plum et al. [33], and Cinkajzlova et al. [34]) compared VLEDs with bariatric surgery, and 3 of them (Paisey et al. [36-38]) compared VLEDs with MER. Figure 1 shows the screening process. Table 1 shows the main characteristics of included trials.

3.2. Evaluation of the Risk of Bias of the Selected Studies. The risk of bias for the included RCTs was assessed using the Cochrane risk of bias tool. None of the RCTs had an overall low risk of bias. Most RCTs had unclear risk of bias for sequence generation, allocation concealment, blinding of participants, blinding of outcome, and selective reporting because no detailed information was provided. However, three studies had high risk of bias for blinding of participants and blinding of outcome assessment, and one study had high risk of bias for allocation concealment because it could not be performed. Moreover, there is incomplete outcome data that most studies had a low risk of bias. Risk of bias assessment of included trials is shown in Figure 2.

The risk of bias for the included non-RCTs according to the ROBINS-I tool is presented in Figure 3. None of the studies had a low or moderate risk of bias, six (Jackness et al. [24], Lips et al. [32], Plum et al. [33], and Paisey et al. [36-38]) had signs of serious bias, and one (Cinkajzlova et al. [34]) had critical bias. The domain "bias due to confounding" was a main source of critical or serious risk of bias. The domain "bias in selection of participants into the study" had moderate or serious risk of bias in all studies. Risk of bias assessment is shown in Figure 3.

\subsection{Meta-Analysis}

\subsubsection{Weight Loss}

(1) VLEDs versus LEDs. Seven studies [25-31] analyzed weight loss when a VLED $(n=246)$ was compared with a LED $(n=241)$. Five of the studies provided data at the end of the intervention, and three provided data in the long-term follow-up ( $\geq 1$ year). Subgroup analyses did result in differences in various time points. When the intervention is completed, the VLED group lost significantly more weight than the comparator arms $(\mathrm{MD}=-2.77 ; 95 \%$ $\left.\mathrm{CI}=-4.81,-0.72 ; P=0.008,<0.05 ; I^{2}=0 \%\right)$. However, when follow-up is $\geq 1$ year, the observed difference in weight loss compared with controls was not significant $(\mathrm{MD}=-0.84$; $95 \% \mathrm{CI}=-3.01,1.32 ; P=0.45 ; I^{2}=0 \%$ ) (Figure 4$)$.

(2) VLEDs versus Bariatric Surgery. Four studies [24, 32, 33, 35 ] analyzed the weight loss between the VLED and surgery groups, including 84 participants. Moreover, the surgical methods used in these four studies were RYGB as comparator arms. The merged data with no evidence of interstudy heterogeneity $\left(I^{2}=0 \%\right)$, according to the DerSimonianLaird FE model, revealed that the VLEDs and RYGB have 


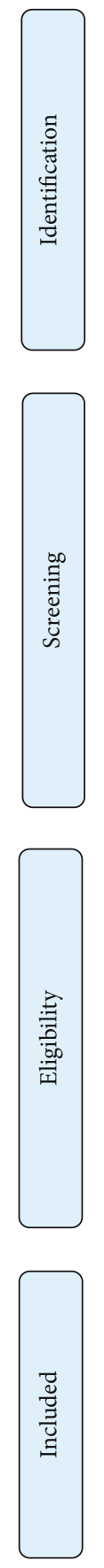

Potentially relevant studies identified and screened for retrieval $(n=6741)$
Additional reference identified from hand

$$
\text { searching }(n=5)
$$

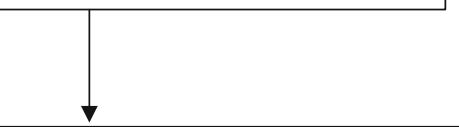

Records after duplicates were removed $(n=4589)$

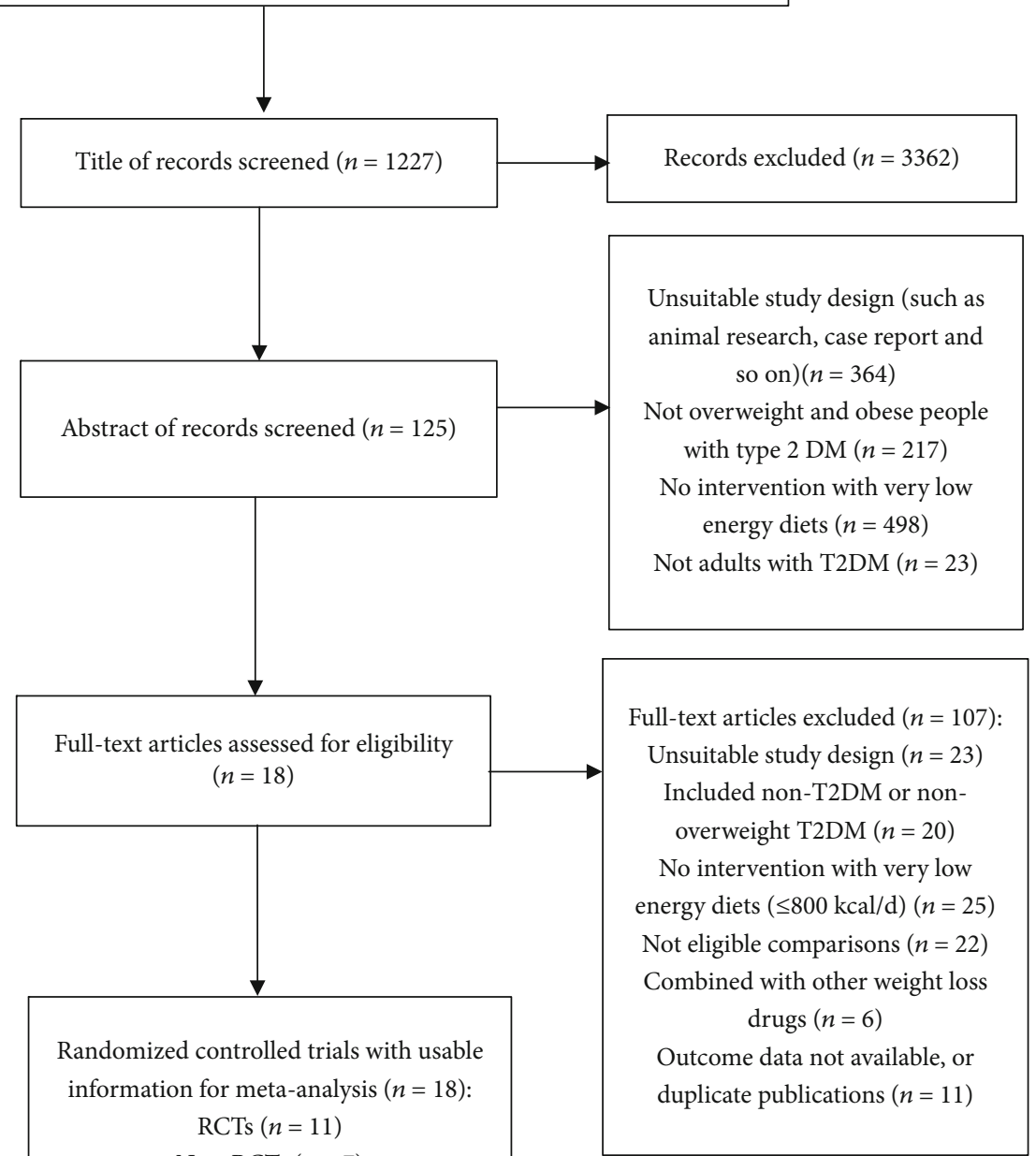

Figure 1: Flow chart of literature search and selection.

similar effects on weight loss, and there is no significant difference between them $(\mathrm{MD}=2.51 ; 95 \% \mathrm{CI}=-9.52,14.54$; $P=0.37,>0.05$ ) (Figure 5).

(3) VLEDs versus MER. Four studies [37-40] analyzed the weight loss when a VLED $(n=88)$ was compared with MER $(n=88)$. Three studies provided data at the end of the intervention, and one provided data for long-term follow-up (5 years). In particular, the study of Williams et al. [40] contains two types of VLED interventions, and that of Paisey et al. [38] contains data for two endpoints.
According to the results of the subgroup analysis, the data at the end of the intervention showed that VLED was significantly better than MER in weight loss $(\mathrm{MD}=-6.72$; 95\%CI $=-10.05,-3.39 ; P<0.0001)$, with evidence of moderate heterogeneity $\left(I^{2}=55 \%\right.$; $\left.P_{\text {heterogeneity }}=0.06\right)$. Sensitivity analysis showed that the heterogeneity was $0 \%$ when "Paisey et al. [38]" was removed, and the effect of VLEDs on weight loss was still significantly better than that of the control $(\mathrm{MD}=-5.19 ; \quad 95 \% \mathrm{CI}=-7.6,-2.78 ; \quad P<0.0001)$. However, when followed up for 5 years, similar to the result of the "Paisey et al. [37]" study, MER was better 


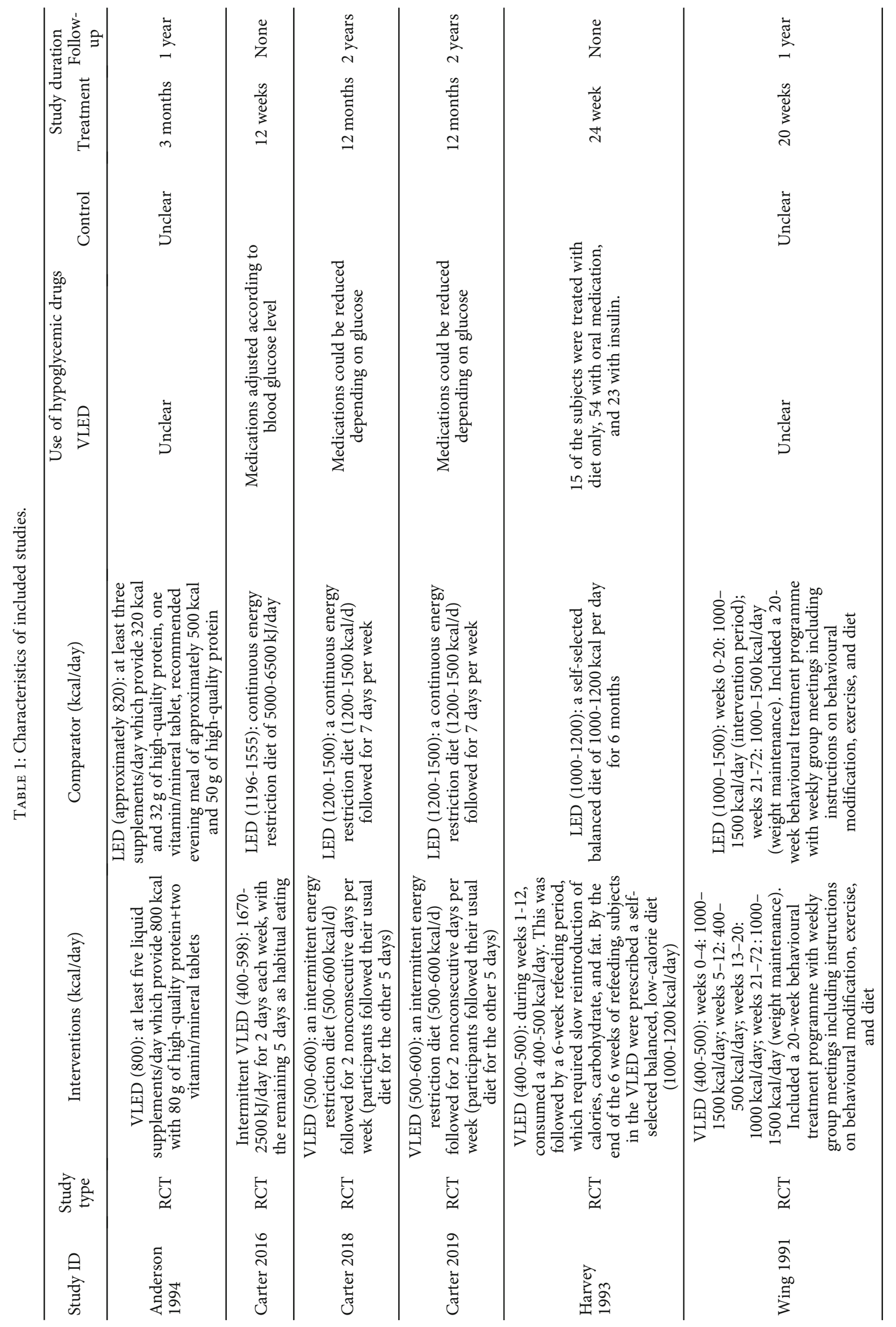




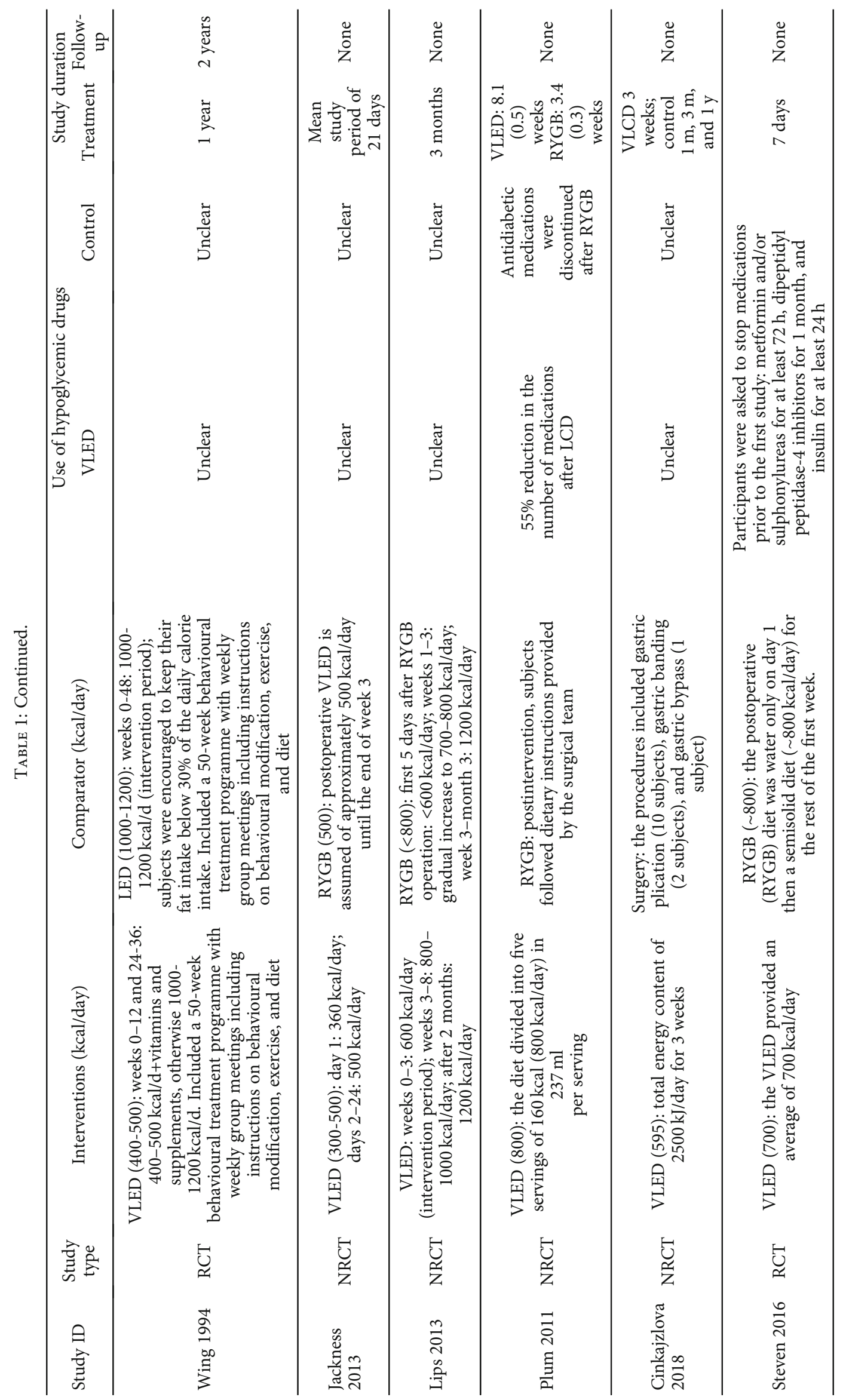




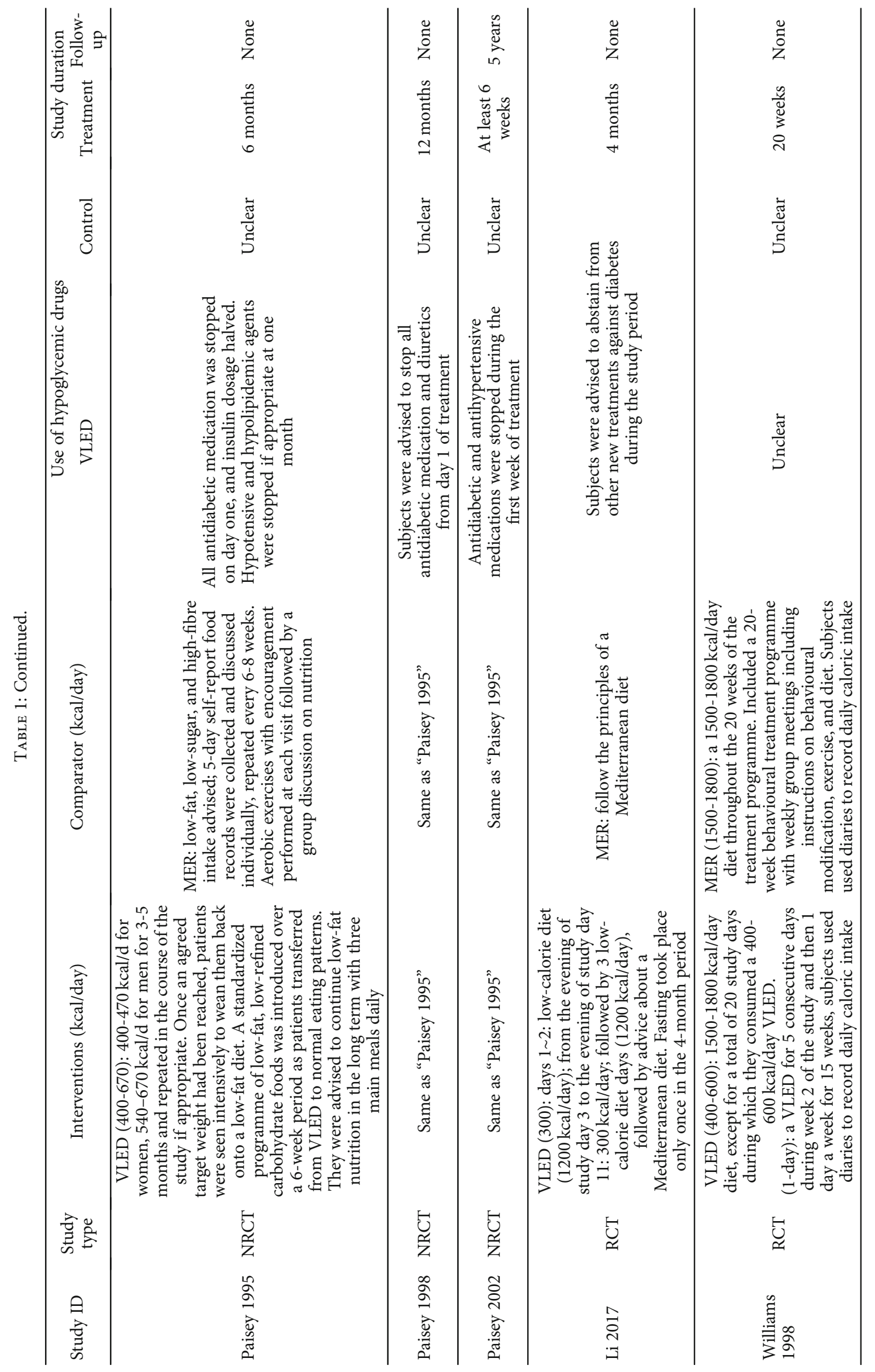




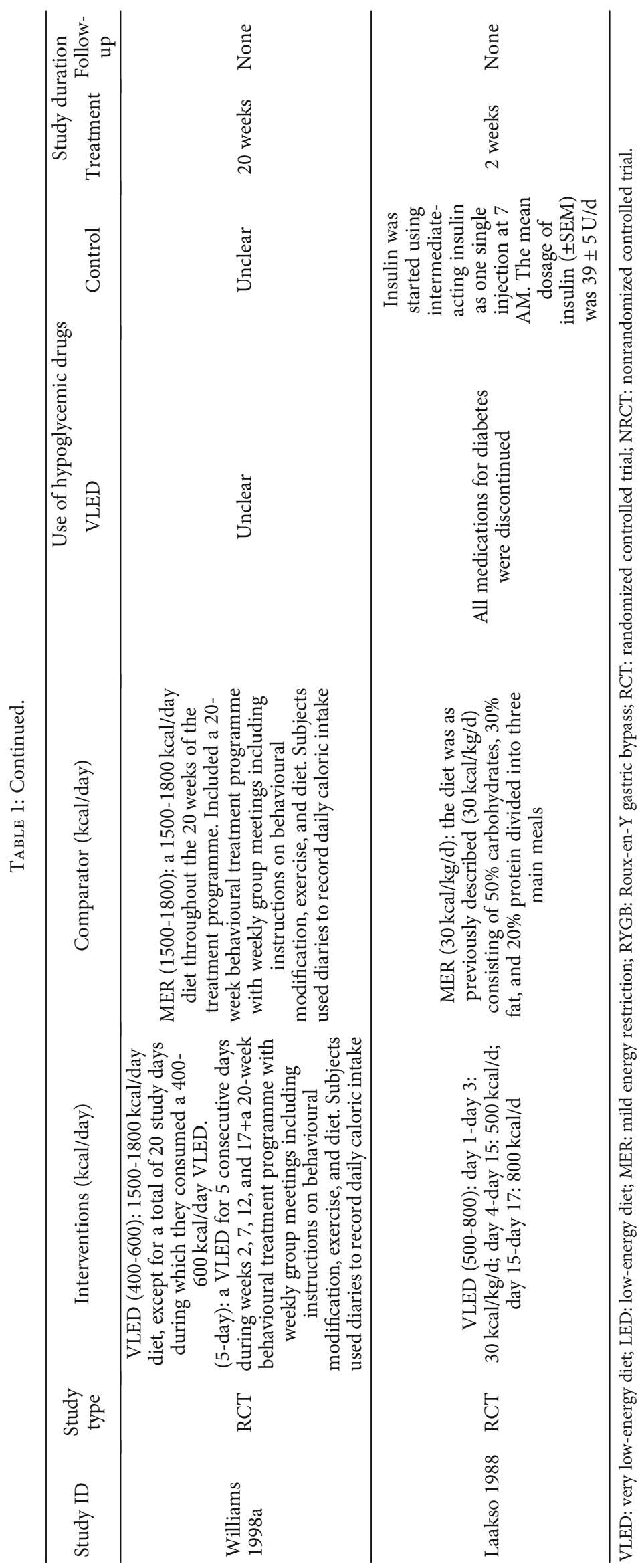




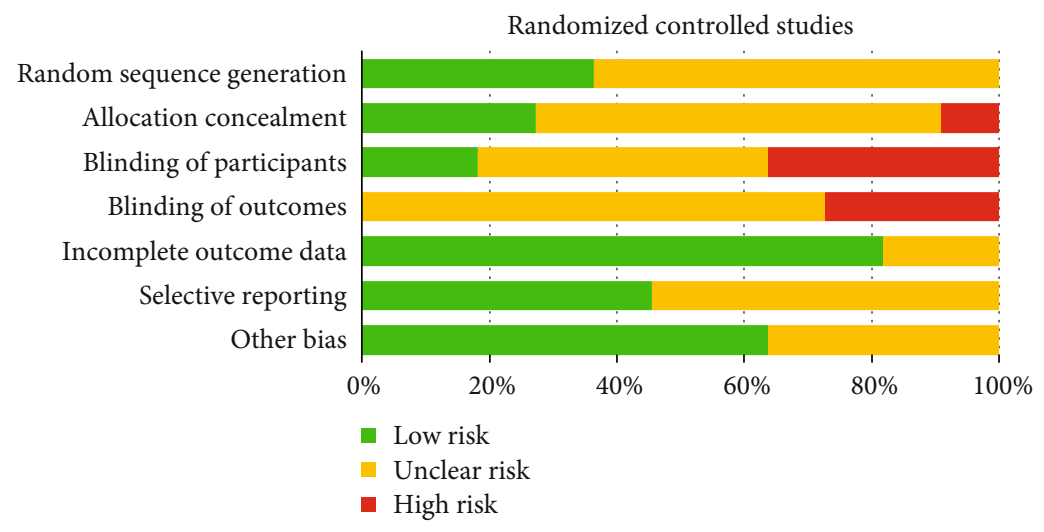

FIGURE 2: Risk of bias summary of included randomized trials with the Cochrane risk of bias tool.

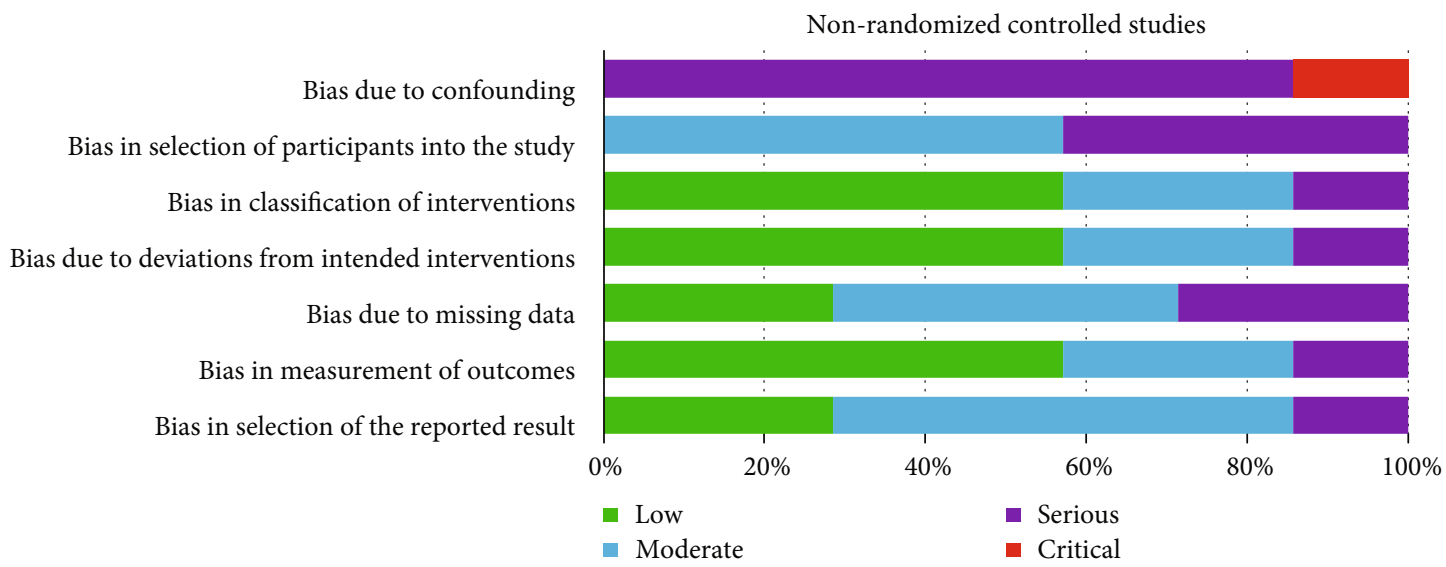

FIgURE 3: Risk of bias summary of included nonrandomized trials with the ROBINS-I tool.

\begin{tabular}{|c|c|c|c|c|c|c|c|c|c|c|c|c|}
\hline \multirow{2}{*}{ Study or subgroup } & \multicolumn{3}{|c|}{ Experimental } & \multicolumn{3}{|c|}{ Control } & \multirow{2}{*}{ Weight } & \multirow{2}{*}{$\begin{array}{l}\text { Mean difference } \\
\text { IV, fixed, } 95 \% \text { CI }\end{array}$} & \multirow{2}{*}{\multicolumn{4}{|c|}{$\begin{array}{l}\text { Mean difference } \\
\text { IV, fixed, } 95 \% \text { CI }\end{array}$}} \\
\hline & Mean & $\mathrm{SD}$ & Total & Mean & SD & Total & & & & & & \\
\hline \multicolumn{13}{|c|}{ 1.1.1 End of intervention } \\
\hline Anderson 1994 & -16.5 & 14.05 & 20 & -14.9 & 13.22 & 19 & $3.0 \%$ & $-1.60[-10.16,6.96]$ & & & & \\
\hline Carter 2016 & -7 & 15.1 & 26 & -5 & 14.1 & 25 & $3.4 \%$ & $-2.00[-10.01,6.01]$ & & & & \\
\hline Carter 2018 & -7.1 & 7.8 & 50 & -5 & 5.3 & 44 & $31.1 \%$ & $-2.10[-4.77,0.57]$ & & & & \\
\hline Harvey 1993 & -17.8 & 7.9 & 38 & -13.8 & 10.5 & 42 & $13.5 \%$ & $-4.00[-8.05,0.05]$ & & & & \\
\hline Wing 1991 & -18.8 & 10.77 & 17 & -10.1 & 20.7 & 16 & $1.7 \%$ & $-8.70[-20.06,2.66]$ & & & & \\
\hline Subtotal $(95 \% \mathrm{CI})$ & & & 151 & & & 146 & $52.8 \%$ & $-2.77[-4.81,-0.72]$ & & & & \\
\hline \multicolumn{13}{|c|}{$\begin{array}{l}\text { Heterogeneity: } \mathrm{chi}^{2}=1.75, \mathrm{df}=4(P=0.78) ; I^{2}=0 \% \\
\text { Test for overall effect: } Z=2.65(P=0.008)\end{array}$} \\
\hline \multicolumn{13}{|c|}{ 1.1.2 Follow-up $\geq 1$ year } \\
\hline Carter 2019 & -4.1 & 7.1 & 42 & -3.7 & 5.8 & 42 & $28.8 \%$ & $-0.40[-3.17,2.37]$ & & & & \\
\hline Wing 1991a & -8.6 & 11.11 & 17 & -6.8 & 19.77 & 16 & $1.8 \%$ & $-1.80[-12.83,9.23]$ & & & & \\
\hline Wing 1994a & -7.2 & 8 & 36 & -5.7 & 7.9 & 37 & $16.6 \%$ & $-1.50[-5.15,2.15]$ & & & & \\
\hline Subtotal (95\% CI) & & & 95 & & & 95 & $47.2 \%$ & $-0.84[-3.01,1.32]$ & & & & \\
\hline \multicolumn{13}{|c|}{$\begin{array}{l}\text { Heterogeneity: } \mathrm{chi}^{2}=0.25, \mathrm{df}=2(P=0.88) ; I^{2}=0 \% \\
\text { Test for overall effect: } Z=0.76(P=0.45)\end{array}$} \\
\hline Total $(95 \%$ CI $)$ & & & 246 & & & 241 & $100.0 \%$ & $-1.86[-3.34,-0.37]$ & & & & \\
\hline \multirow{2}{*}{\multicolumn{9}{|c|}{$\begin{array}{l}\text { Heterogeneity: } \text { chi }^{2}=3.60, \mathrm{df}=7(P=0.82) ; I^{2}=0 \% \\
\text { Test for overall effect: } Z=2.45(P=0.01)\end{array}$}} & -20 & -10 & 10 & 20 \\
\hline & & & & & & & & & Fave & [exper & Favours [ & [control] \\
\hline
\end{tabular}

FIGURE 4: Forest plot on the mean difference in weight loss between VLED and LED controls. 


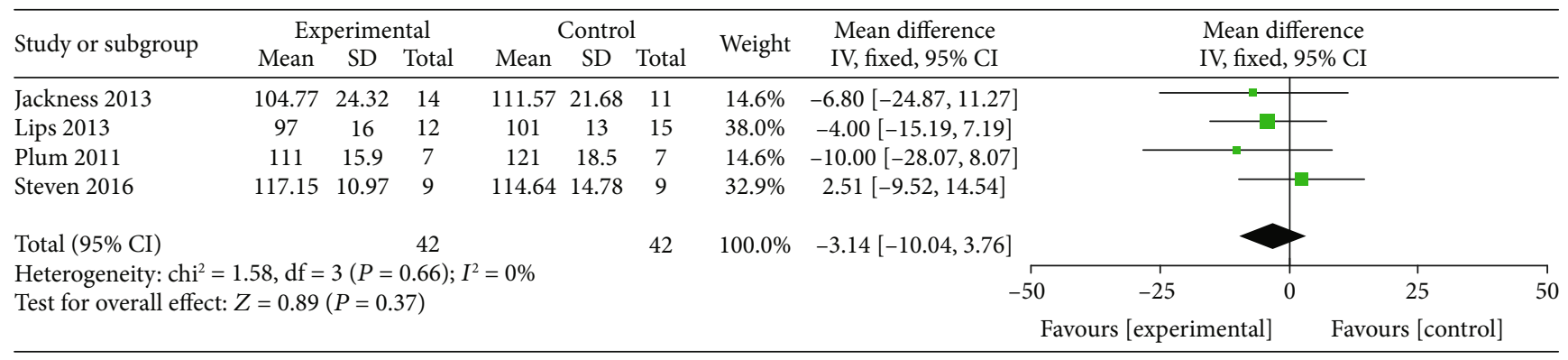

FIGURE 5: Forest plot on the mean difference in weight loss among VLED and bariatric surgery controls.

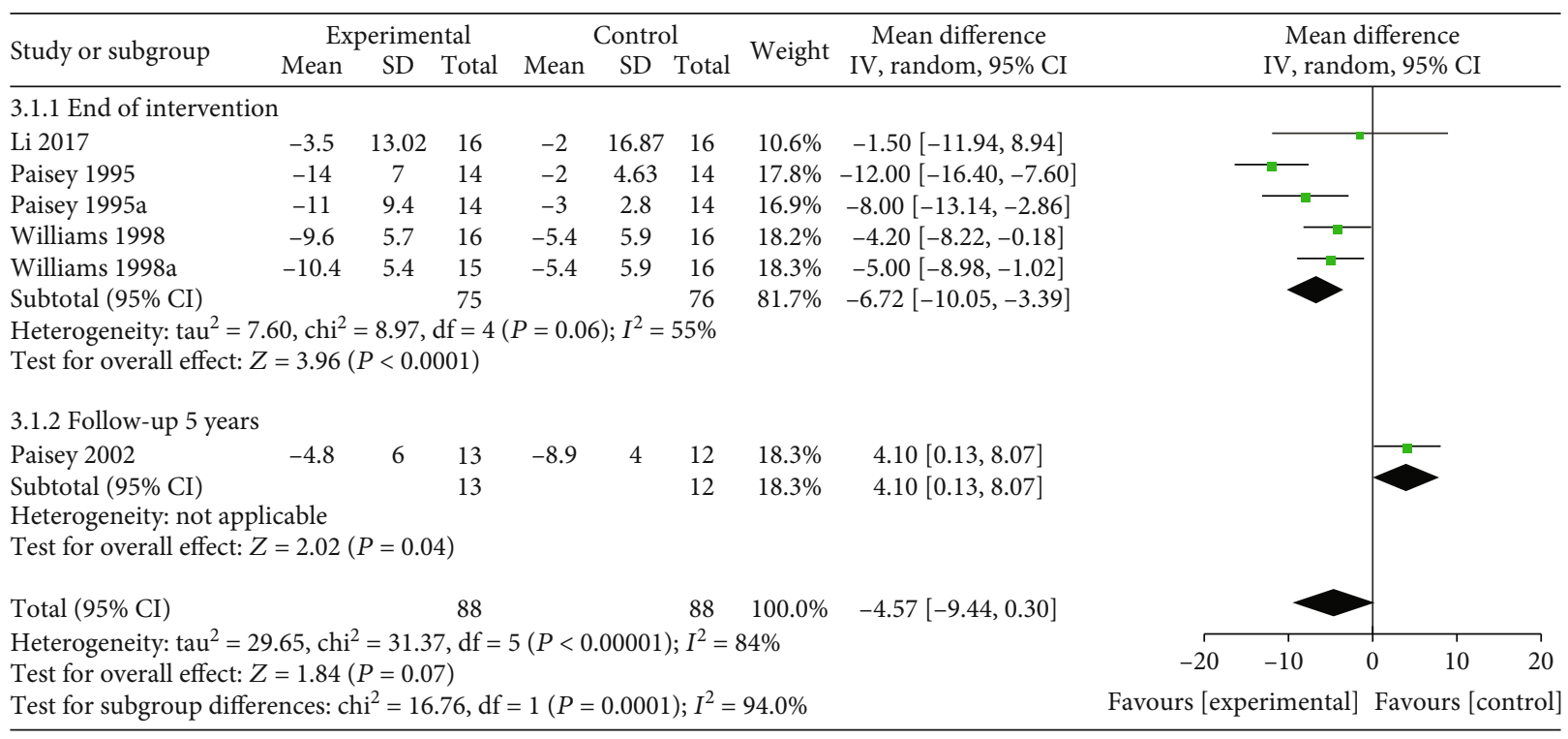

FIGURE 6: Forest plot on the mean difference in weight loss between VLED and MER controls.

maintained than VLEDs $(\mathrm{MD}=4.1 ; 95 \% \mathrm{CI}=0.13,8.07$; $P=0.06$ ) (Figure 6).

\subsubsection{Blood Glucose and Changes in Medication}

(1) VLEDs versus LEDs. Four studies [25, 28, 30, 31] analyzed the blood glucose levels between the VLED and LED groups, and all of them provided data at the end of the intervention. Simultaneously, two provided data for long-term follow-up ( $\geq 1$ year). A significant difference in weight change in favor of the intervention arm was noted at both the end of the intervention $(\mathrm{MD}=-1.18 ; 95 \% \mathrm{CI}=-2.05,-0.30 ; P=0.008$, $<0.05)$ and follow-up $(\mathrm{MD}=-1.43 ; 95 \% \mathrm{CI}=-2.65,-0.20$; $P=0.02,<0.05)$, and both of them had no evidence of interstudy heterogeneity $\left(I^{2}=0 \%\right)$. Regarding the use of hypoglycemic drugs, Carter et al. reported that although medication dose decreased with time, all participants using medication at baseline were also using medication at the end of the study. At 2 years, one study (Wing et al. [31]) reported that fewer participants in the VLED group required medication ( $45 \%$ vs. $69 \%$ in the VLED and LED groups, respectively) (Figure 7).
(2) VLEDs versus Bariatric Surgery. Five studies [24, 32-35] analyzed the blood glucose levels between the VLED $(n=69)$ and bariatric surgery groups $(n=55)$. The merged data with no evidence of interstudy heterogeneity $\left(I^{2}=\right.$ $49 \%$ ), according to the DerSimonian-Laird FE model, revealed that VLEDs and surgery have similar effects on weight loss, and there is no significant difference between them $(\mathrm{MD}=0.37 ; 95 \% \mathrm{CI}=-0.22,0.96 ; P=0.22,>0.05)$ (Figure 8). In the use of hypoglycemic drugs, one study [33] showed that all hypoglycemic drugs were discontinued in the RYGB arm and decreased by 55\% in the VLED arm after the intervention. In another study [32], metformin was reintroduced in 4/15 participants in the RYGB arm and 2/12 participants in the VLED arm after the intervention, and the difference was not significant.

(3) VLEDs versus MER. Five studies [36, 37, 39-41] analyzed the blood glucose levels between the VLED $(n=86)$ and MER groups $(n=84)$. Results from the subgroup analyses showed that VLED was significantly better than MER in lowering blood glucose levels $(\mathrm{MD}=-6.72 ; 95 \% \mathrm{CI}=-10.05,-3.39$; $P<0.0001)$ at the end of the intervention, with evidence 


\begin{tabular}{|c|c|c|c|c|c|c|c|c|c|c|}
\hline \multirow{2}{*}{ Study or subgroup } & \multicolumn{3}{|c|}{ Experimental } & \multicolumn{3}{|c|}{ Control } & \multirow{2}{*}{ Weight } & \multirow{2}{*}{$\begin{array}{l}\text { Mean difference } \\
\text { IV, fixed, 95\% CI }\end{array}$} & \multirow{2}{*}{\multicolumn{2}{|c|}{$\begin{array}{l}\text { Mean difference } \\
\text { IV, fixed, } 95 \% \mathrm{CI}\end{array}$}} \\
\hline & Mean & SD & Total & Mean & SD & Total & & & & \\
\hline \multicolumn{11}{|c|}{ 1.2.1 End of intervention } \\
\hline Anderson 1994 & 7.6 & 2.24 & 20 & 8.9 & 3.49 & 19 & $14.8 \%$ & $-1.30[-3.15,0.55]$ & & \\
\hline Wing 1991 & 7.7 & 2.1 & 17 & 9.3 & 1.7 & 16 & $30.0 \%$ & $-1.60[-2.90,-0.30]$ & & \\
\hline Wing 1994 & 9.28 & 3.67 & 38 & 9.78 & 3.28 & 41 & $21.4 \%$ & $-0.50[-2.04,1.04]$ & & \\
\hline Subtotal (95\% CI) & & & 75 & & & 76 & $66.2 \%$ & $-1.18[-2.05,-0.30]$ & & \\
\hline \multicolumn{11}{|c|}{$\begin{array}{l}\text { Heterogeneity: } \mathrm{chi}^{2}=1.17, \mathrm{df}=2(P=0.56) ; I^{2}=0 \% \\
\text { Test for overall effect: } Z=2.64(P=0.008)\end{array}$} \\
\hline \multicolumn{11}{|c|}{ 1.2.2 Follow-up $\geq 1$ year } \\
\hline Carter 2019 & 8.1 & 4.36 & 59 & 8.5 & 4.97 & 51 & $16.4 \%$ & $-0.40[-2.16,1.36]$ & & \\
\hline Wing 1991a & 10.4 & 4.1 & 17 & 13.5 & 3.2 & 16 & $8.1 \%$ & $-3.10[-5.60,-0.60]$ & & \\
\hline Wing $1994 \mathrm{a}$ & 11.01 & 4.84 & 36 & 12.79 & 5.35 & 37 & $9.3 \%$ & $-1.78[-4.12,0.56]$ & & \\
\hline Subtotal (95\% CI) & & & 112 & & & 104 & $33.8 \%$ & $-1.43[-2.65,-0.20]$ & & \\
\hline \multicolumn{11}{|c|}{$\begin{array}{l}\text { Heterogeneity: } \text { chi }^{2}=3.11, \mathrm{df}=2(P=0.21) ; I^{2}=36 \% \\
\text { Test for overall effect: } Z=2.28(P=0.02)\end{array}$} \\
\hline Total $(95 \%$ CI $)$ & & & 187 & & & 180 & $100.0 \%$ & $-1.26[-1.97,-0.55]$ & & \\
\hline \multicolumn{9}{|c|}{ Heterogeneity: $\mathrm{chi}^{2}=4.39, \mathrm{df}=5(P=0.50) ; I^{2}=0 \%$} & Favours [experimental] & $\begin{array}{cc}2 & 4 \\
\text { Favours [control] }\end{array}$ \\
\hline
\end{tabular}

FIGURE 7: Forest plot on the mean difference in blood glucose levels between VLED and LED controls.

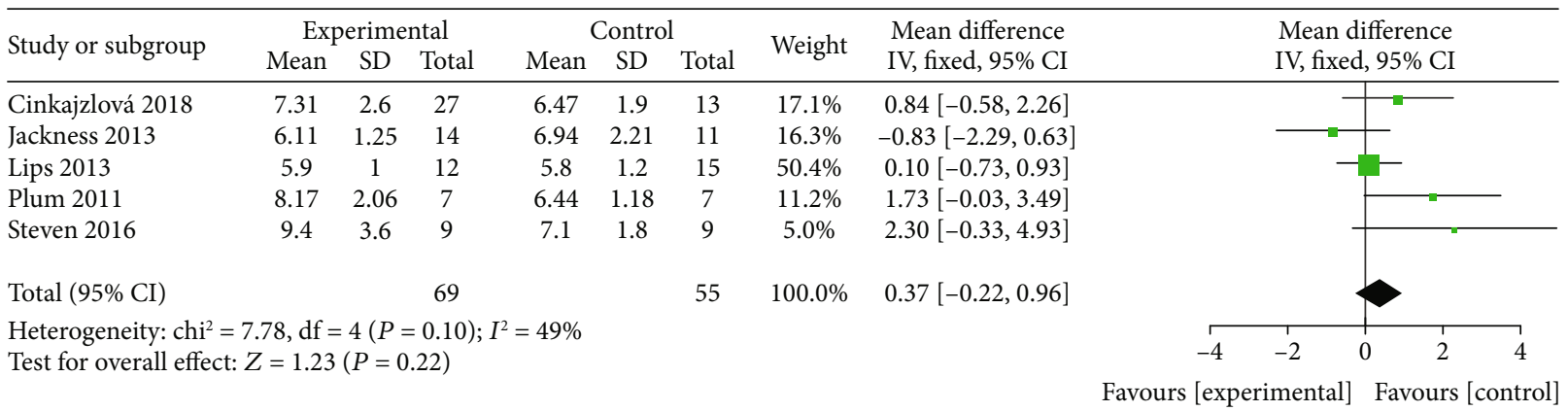

FIGURE 8: Forest plot on the mean difference of glucose among VLED and bariatric surgery controls.

of low heterogeneity $\left(I^{2}=48 \% ; P_{\text {heterogeneity }}=0.17\right)$. However, at the 5-year follow-up, only one study by "Paisey et al. [37]" reported that the difference in blood glucose levels compared with controls was not significant $(\mathrm{MD}=-1 ; 95 \% \mathrm{CI}=-4.62,2.62 ; P=0.59)$. In the use of hypoglycemic drugs at the end of the intervention, the study of Paisey et al. showed that, at 6 months (all patients who underwent VLEDs had reverted to normal food for at least two weeks), the patients in the VLED group discontinued insulin, sulphonylureas, or hypolipidemic agents, while patients in the MER group were not able to discontinue their antidiabetic or hypolipidemic therapies. At 1 year, 14 of 15 patients in the VLED group, but none in the conventional diet group, had discontinued insulin and any oral hypoglycemic medication (Figure 9).

\subsection{3. $T G$}

(1) VLEDs versus LEDs. Four studies [25, 28, 30, 31] analyzed the TG level between the VLED $(n=185)$ and LED groups $(n=179)$. All studies provided data at the end of the intervention, and two provided data in the long-term follow-up ( $\geq 1$ year). Results from subgroup analyses showed that the
VLED group had significantly lower TG level than the comparator arms at the end of the intervention $(\mathrm{MD}=-0.35$; $\left.95 \% \mathrm{CI}=-0.58,-0.12 ; P=0.002,<0.05 ; I^{2}=38 \%\right)$. However, when the follow-up duration is $\geq 1$ year, the observed difference in the TG level compared with controls was not significant $(\mathrm{MD}=-0.25 ; 95 \% \mathrm{CI}=-0.55,0.06 ; \quad P=0.12, \quad>0.05$; $I^{2}=0 \%$ ) (Figure 10).

(2) VLEDs versus Bariatric Surgery. Four studies [24, 33-35] analyzed the TG levels between the VLED $(n=57)$ and bariatric surgery groups $(n=40)$. The merged data, which had no evidence of interstudy heterogeneity $\left(I^{2}=2 \%\right)$, according to the DerSimonian-Laird FE model, revealed that VLEDs and surgery have similar effects on weight loss, and there is no significant difference between them $(\mathrm{MD}=-0.3$; $95 \% \mathrm{CI}=-0.74,0.17 ; P=0.7,>0.05$ ) (Figure 11).

(3) VLEDs versus MER. Four studies [37-40] analyzed the TG levels between the VLED $(n=88)$ and MER groups $(n=84)$. Results from subgroup analyses showed that a VLED was significantly better than MER in lowering TG levels $(\mathrm{MD}=-0.55 ; 95 \% \mathrm{CI}=-0.93,-0.17 ; P=0.005,<0.05)$ at the end of the intervention, with no evidence of interstudy 


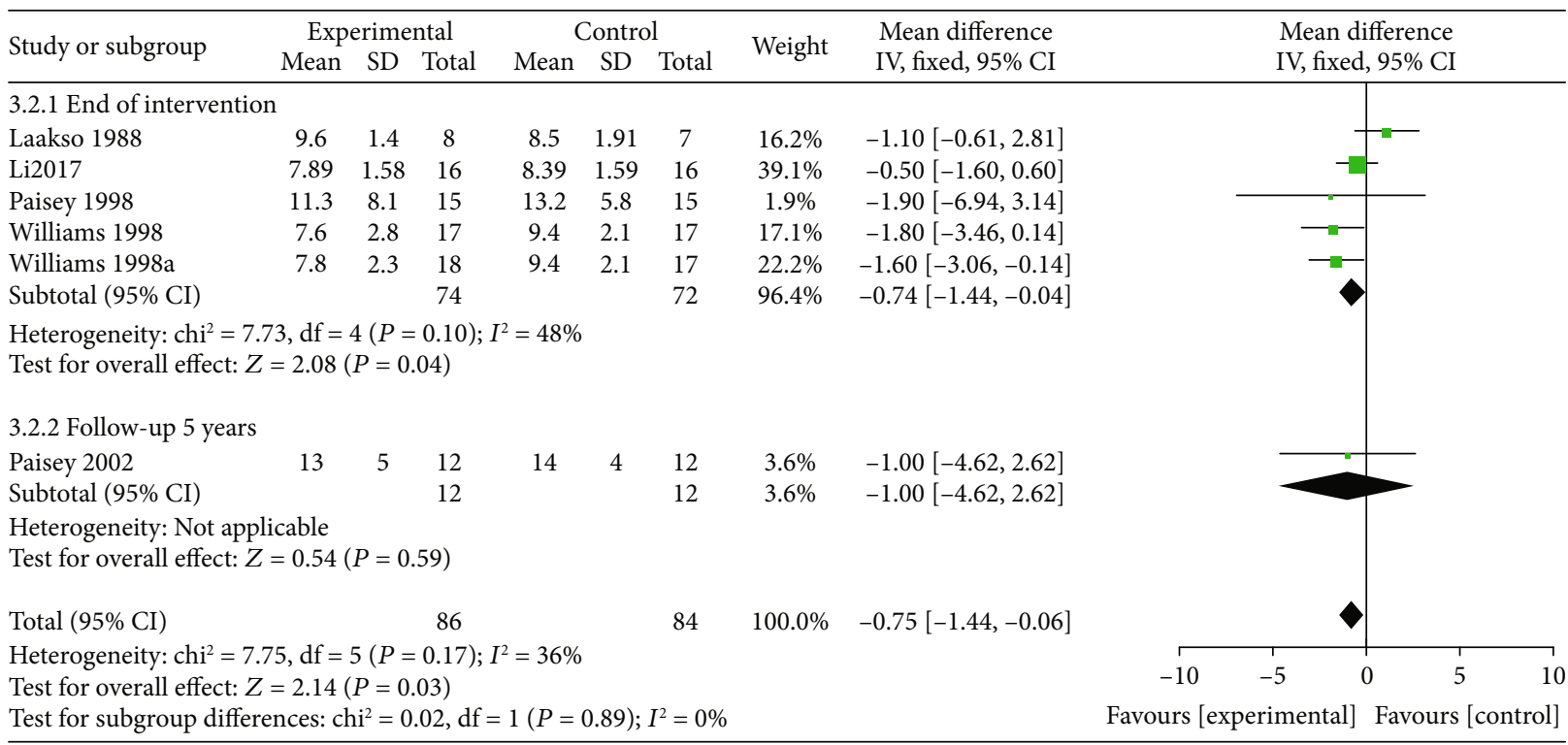

FIgURE 9: Forest plot on the mean difference in blood glucose levels between VLED and MER controls.

\begin{tabular}{|c|c|c|c|c|c|c|c|c|c|c|c|c|}
\hline \multirow{2}{*}{ Study or subgroup } & \multicolumn{3}{|c|}{ Experimental } & \multicolumn{3}{|c|}{ Control } & \multirow{2}{*}{ Weight } & \multirow{2}{*}{$\begin{array}{l}\text { Mean difference } \\
\text { IV, fixed, 95\% CI }\end{array}$} & \multirow{2}{*}{\multicolumn{4}{|c|}{$\begin{array}{l}\text { Mean difference } \\
\text { IV, fixed, 95\% CI }\end{array}$}} \\
\hline & Mean & $\mathrm{SD}$ & Total & Mean & $\mathrm{SD}$ & Total & & & & & & \\
\hline \multicolumn{13}{|c|}{ 1.4.1 End of intervention } \\
\hline Anderson 1994 & 1.7 & 0.89 & 20 & 2 & 0.87 & 19 & $10.8 \%$ & $-0.30[-0.85,0.25]$ & & & & \\
\hline Wing 1991 & 1.02 & 0.32 & 17 & 1.61 & 0.65 & 16 & $26.5 \%$ & $-0.59[-0.94,-0.24]$ & & & & \\
\hline Wing 1994 & 1.45 & 0.67 & 38 & 1.59 & 0.89 & 41 & $27.6 \%$ & $-0.14[-0.49,0.21]$ & & & & \\
\hline Subtotal (95\% CI) & & & 75 & & & 76 & $65.0 \%$ & $-0.35[-0.58,-0.12]$ & & & & \\
\hline \multicolumn{13}{|c|}{$\begin{array}{l}\text { Heterogeneity: } \text { chi }^{2}=3.22, \mathrm{df}=2(P=0.20) ; I^{2}=38 \% \\
\text { Test for overall effect: } Z=3.05(P=0.002)\end{array}$} \\
\hline \multicolumn{13}{|c|}{ 1.4.2 Follow-up $\geq 1$ year } \\
\hline Carter 2019 & 1.48 & 1.72 & 55 & 1.7 & 2.29 & 46 & $5.1 \%$ & $-0.22[-1.02,0.58]$ & & & & \\
\hline Wing 1991a & 1.65 & 0.81 & 17 & 2.21 & 1.2 & 16 & $6.7 \%$ & $-0.56[-1.26,0.14]$ & & & & \\
\hline Wing 1994a & 1.5 & 0.78 & 38 & 1.66 & 0.93 & 41 & $23.2 \%$ & $-0.16[-0.54,0.22]$ & & & & \\
\hline Subtotal (95\% CI) & & & 110 & & & 103 & $35.0 \%$ & $-0.25[-0.55,0.06]$ & & & & \\
\hline \multicolumn{13}{|c|}{$\begin{array}{l}\text { Heterogeneity: } \text { chi }^{2}=0.97, \mathrm{df}=2(P=0.62) ; I^{2}=0 \% \\
\text { Test for overall effect: } Z=1.56(P=0.12)\end{array}$} \\
\hline Total (95\% CI) & & & 185 & & & 178 & $100.0 \%$ & $-0.31[-0.50,-0.13]$ & & & & \\
\hline \multirow{2}{*}{\multicolumn{9}{|c|}{$\begin{array}{l}\text { Heterogeneity: } \text { chi }^{2}=4.49, \mathrm{df}=5(P=0.48) ; I^{2}=0 \% \\
\text { Test for overall effect: } Z=3.38(P=0.0007) \\
\text { Test for subgroup differences: } \mathrm{chi}^{2}=0.29, \mathrm{df}=1(P=0.59) ; I^{2}=0 \%\end{array}$}} & -1 & -0.5 & 0.5 & ᄀ \\
\hline & & & & & & & & & Favours [exp & erimental] & Favours & ontrol] \\
\hline
\end{tabular}

FIGURE 10: Forest plot on the mean difference in TG levels between VLED and LED controls.

heterogeneity $\left(I^{2}=23 \% ; P_{\text {heterogeneity }}=0.25\right)$. However, at the 5-year follow-up, similar to the result of the "Paisey et al. [37]" study, the difference in lowering TG level compared with controls was not significant $(\mathrm{MD}=0.4 ; 95 \%$ $\mathrm{CI}=-1.11,1.91 ; P=0.60$ ) (Figure 12).

3.3.4. HOMA-IR. Four studies [24, 32-34] analyzed the change in HOMA-IR between the VLED $(n=60)$ and bariatric surgery groups $(n=46)$, and one study analyzed the change in HOMA-IR between the VLED $(n=75)$ and MER groups $(n=76)$. The meta-analysis showed that there was no significant difference between VLEDs and surgery in increasing HOMA-IR $(\mathrm{MD}=-1 ; 95 \% \mathrm{CI}=-2.7,0.7 ; P=$ $0.25,>0.05$ ) (Figure 13). Additionally, one study ( $\mathrm{Li}$ et al.
[39]) reported that nonsignificant improvements in HOMA-IR were also observed between the VLED and MER groups.

3.3.5. Dropout. Comparing the VLED and bariatric surgery groups, no loss of patients was reported. However, most studies on VLEDs compared with those on LEDs or MER reported increased dropout rate.

(1) VLEDs versus LEDs. Six studies [25-28, 30, 31] reported the difference in dropout rate between the VLED $(n=253)$ and LED groups $(n=253)$. The meta-analyses showed that the VLED group had a similar dropout rate with the comparator arms $(\mathrm{OR}=0.74 ; 95 \% \mathrm{CI}=0.49,1.13 ; P=0.16,>0.05$; $I^{2}=0 \%$ ) (Figure 14). 


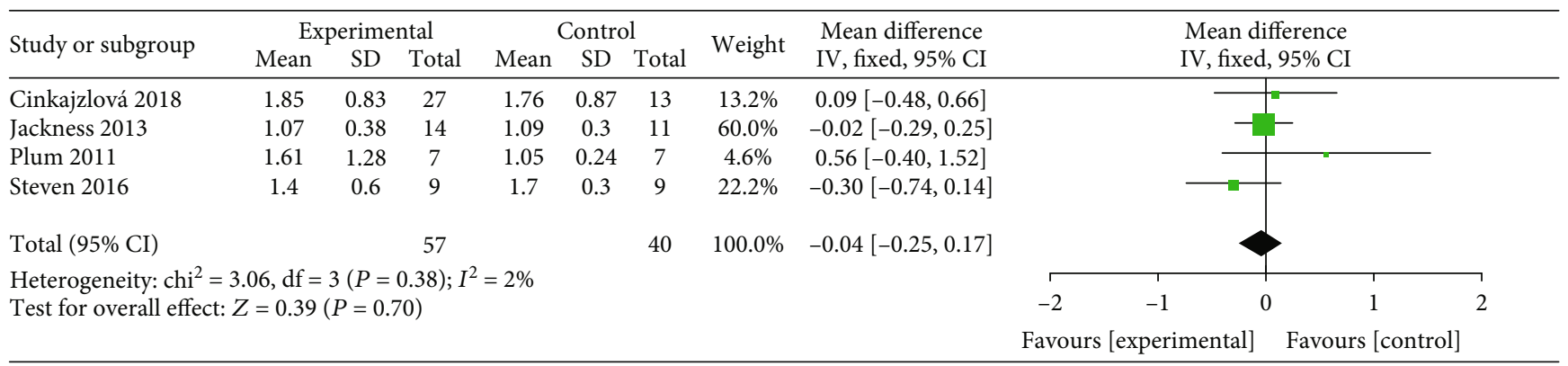

FIGURE 11: Forest plot on the mean difference in TG levels between VLED and bariatric surgery controls.

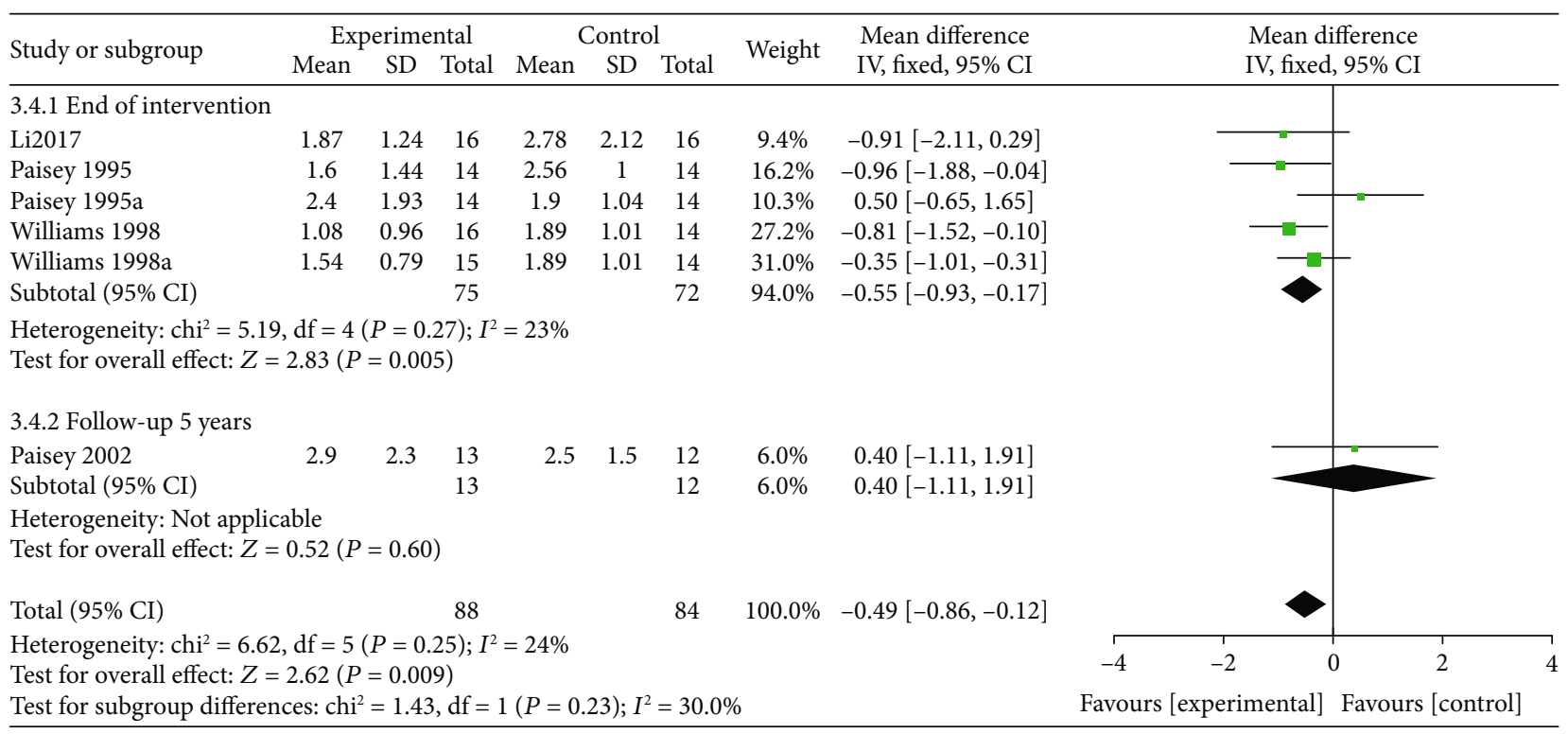

FIGURE 12: Forest plot on the mean difference in TG levels between VLED and MER controls.

\begin{tabular}{|c|c|c|c|c|c|c|c|c|c|c|c|c|}
\hline \multirow{3}{*}{$\begin{array}{l}\text { Study or subgroup } \\
\text { Cinkajzlová } 2018\end{array}$} & \multicolumn{3}{|c|}{ Experimental } & \multicolumn{3}{|c|}{ Control } & \multirow{2}{*}{ Weight } & \multirow{2}{*}{$\begin{array}{l}\text { Mean difference } \\
\text { IV, random, 95\% CI }\end{array}$} & & \multirow{2}{*}{\multicolumn{3}{|c|}{$\begin{array}{l}\text { Mean difference } \\
\text { IV, random, 95\% CI }\end{array}$}} \\
\hline & Mean & $\mathrm{SD}$ & Total & Mean & SD & Total & & & & & & \\
\hline & 11.83 & 1.18 & 27 & 19.95 & 8.93 & 13 & $8.8 \%$ & $-8.12[-12.99,-3.25]$ & \multirow[t]{4}{*}{$\leftarrow$} & \multirow{4}{*}{-} & \multirow{4}{*}{\multicolumn{2}{|c|}{ - - }} \\
\hline Jackness 2013 & 1.8 & 0.4 & 14 & 3.5 & 0.6 & 11 & $31.7 \%$ & $-1.70[-2.11,-1.29]$ & & & & \\
\hline Lips 2013 & 1.3 & 0.9 & 12 & 1.8 & 1 & 15 & $30.5 \%$ & $-0.50[-1.22,0.22]$ & & & & \\
\hline Plum 2011 & 5.6 & 1.1 & 7 & 4.2 & 0.8 & 7 & $29.0 \%$ & $1.40[0.39,2.41]$ & & & & \\
\hline Total $(95 \% \mathrm{CI})$ & & & 60 & & & 46 & $100.0 \%$ & $-1.00[-2.70,0.70]$ & & & & \\
\hline \multicolumn{9}{|c|}{$\begin{array}{l}\text { Heterogeneity: } \operatorname{tau}^{2}=2.33, \mathrm{chi}^{2}=42.43, \mathrm{df}=3(P<0.00001) ; I^{2}=93 \% \\
\text { Test for overall effect: } Z=1.16(P=0.25)\end{array}$} & -4 & -2 & 2 & 4 \\
\hline
\end{tabular}

FIGURE 13: Forest plot on the mean difference in HOMA-IR between VLED and bariatric surgery controls.

(2) VLEDs versus MER. Five studies [36, 37, 39-41] reported the difference in dropout rates between the VLED $(n=97)$ and MER groups $(n=97)$. Results from the meta-analyses showed that the VLED group had a similar dropout rate with the MER group $(\mathrm{OR}=0.68 ; 95 \% \mathrm{CI}=0.32,1.48 ; P=0.33$, $>0.05)$ with no evidence of interstudy heterogeneity $\left(I^{2}=0 \% ; P_{\text {heterogeneity }}=0.93\right)($ Figure 15$)$.

3.3.6. Side Effects. Nine of 18 studies involved reports of adverse reactions. Adverse reactions reported by Carter et al. [26, 27] were mainly hypoglycemia, hyperglycemia, and headache. Paisey et al. [36-38] reported adverse reactions such as hypoglycemia. myocardial infarction, and telogen effluvium. Wing et al. [30, 31] mainly reported adverse reactions such as cold intolerance, constipation, and hair loss. Andorson's study showed that frequently reported side effects during the weight loss phase included constipation, diarrhea, dizziness, and fatigue. The adverse reactions reported in Li et al.'s study were slight headache and dizziness during energy restriction. None of these studies reported significant differences in side effects between the VLED and control groups (see Table 2 for details). 


\begin{tabular}{|c|c|c|c|c|c|c|c|c|c|c|}
\hline \multirow{3}{*}{$\begin{array}{l}\text { Study or subgroup } \\
\text { Anderson } 1994\end{array}$} & \multicolumn{2}{|c|}{ Experimental } & \multicolumn{2}{|c|}{ Control } & \multirow{3}{*}{$\begin{array}{c}\text { Weight } \\
2.8 \%\end{array}$} & \multirow{3}{*}{$\begin{array}{c}\text { Odds ratio } \\
\text { M-H, fixed, 95\% CI } \\
0.32[0.01,8.26]\end{array}$} & \multirow{2}{*}{\multicolumn{4}{|c|}{$\begin{array}{c}\text { Odds ratio } \\
\text { M-H, fixed, } 95 \% \text { CI }\end{array}$}} \\
\hline & \multirow{2}{*}{$\frac{\text { Events }}{0}$} & \multirow{2}{*}{$\begin{array}{c}\text { Total } \\
20\end{array}$} & \multirow{2}{*}{$\frac{\text { Events }}{1}$} & \multirow{2}{*}{$\frac{\text { Total }}{20}$} & & & & & & \\
\hline & & & & & & & & & & \\
\hline Carter 2016 & 5 & 31 & 7 & 32 & $11.2 \%$ & $0.69[0.19,2.45]$ & & & & \\
\hline Carter 2018 & 20 & 70 & 23 & 67 & $32.7 \%$ & $0.77[0.37,1.58]$ & & & & \\
\hline Carter 2019 & 28 & 70 & 25 & 67 & $29.8 \%$ & $1.12[0.56,2.23]$ & & & & \\
\hline Wing 1991 & 0 & 17 & 3 & 19 & $6.3 \%$ & $0.13[0.01,2.81]$ & & & & \\
\hline Wing 1994 & 4 & 45 & 10 & 48 & $17.2 \%$ & $0.37[0.11,1.28]$ & & & & \\
\hline Total (95\% CI) & & 253 & & 253 & $100.0 \%$ & $0.74[0.49,1.13]$ & & & & \\
\hline Total events & 57 & & 69 & & & & & & & \\
\hline $\begin{array}{l}\text { Heterogeneity: } \text { chi }^{2} \\
\text { Test for overall effec }\end{array}$ & $\begin{array}{l}f=5(P= \\
40(P=0\end{array}$ & $\begin{array}{l}0.54) \text {; } \\
16)\end{array}$ & $=0 \%$ & & & & 0.01 & 0.1 & 10 & 100 \\
\hline & & & & & & & & exper & [cont & \\
\hline
\end{tabular}

FIGURE 14: Forest plot of dropout rates between VLED and LED controls.

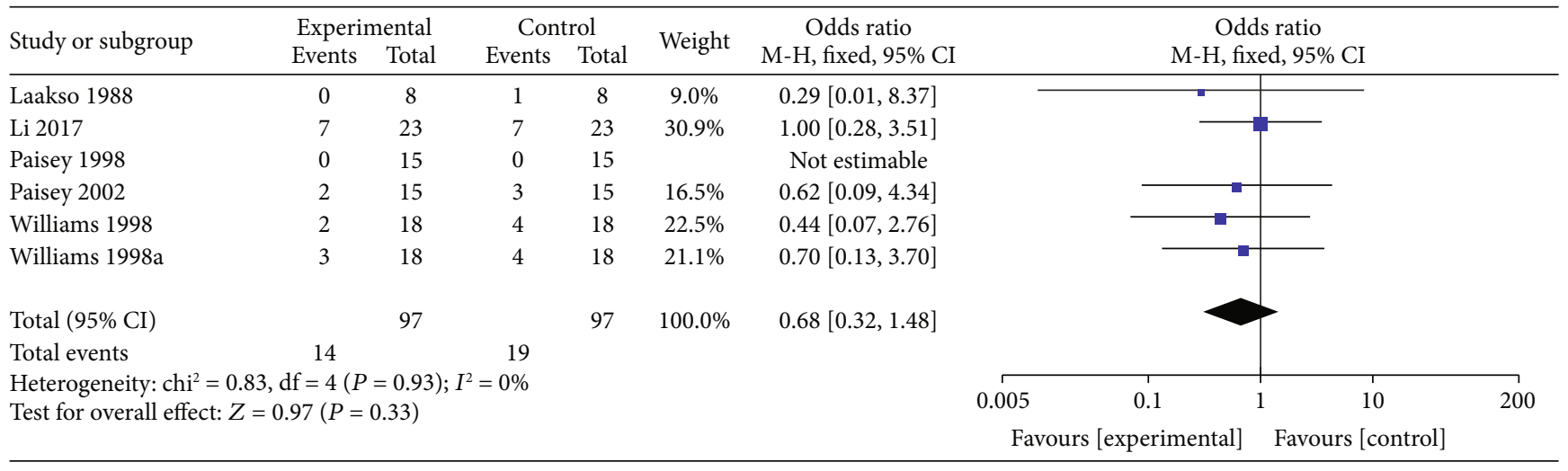

FIGURE 15: Forest plot of dropout rate between VLED and MER controls.

3.3.7. Rebound. Only three studies mentioned a rebound in body weight, blood glucose level, and other indicators after energy restriction therapy. One study [28] reported that at 24 months, in the completer analysis of 84 participants at follow-up, 44 (52\%) regained weight (>1 kg weight gain) and participants regained $33 \%$ of their weight losses between 12 and 24 months. In this follow-up study, HbA1c level had increased by $0.3 \%(3.3 \mathrm{mmol} / \mathrm{mol})$ from baseline at 24 months. Paisey et al. [37] found that weight loss was slower in the intensive conventional diet group than in the VLED group but better maintained at 5 years: group $1,4.8 \pm 6 \mathrm{~kg}$, and group 2, $8.9 \pm 4 \mathrm{~kg}$. Wing et al. [30, 31] reported that, although initial weight losses were greater in the VLED group, these participants regained significantly more weight than those in the behavioural therapy group in 1 year of follow-up. Moreover, at one-year assessment, the measures of glycemic control had returned to baseline, and no differences were observed between treatment groups.

3.4. Publication Bias. All outcome indicators were analyzed in $<10$ studies, so publication bias was not examined.

3.5. GRADE for the Outcomes. We evaluated all outcome indicators by GRADEprofiler 3.6 from the following aspects: (1) downgrade quality of evidence, risk of bias, inconsistency, indirectness, imprecision, and publication bias and
(2) upgrade quality of evidence, large effect, plausible confounding changing the effect, and dose-response gradient.

After a comprehensive analysis, the evidentiary body was formed and found that all outcome indicators had low quality or extremely low quality (see Tables 3-5 for details).

\section{Discussion}

Our systematic review provides evidence based on current clinical trials on the efficacy of continuous and intermittent VLEDs in overweight and obese individuals with T2DM by comparison to other methods of energy restriction. First, during the intervention period, a VLED is superior in the reduction of body weight and blood glucose and TG levels to LEDs and MER. After long-term follow-up, there is no obvious difference in weight loss between VLEDs and LEDs, but glycemic control is still more effective in VLEDs. Second, VLEDs offer beneficial effects on weight loss, glycemic control, and improvement of insulin resistance comparable to bariatric surgery.

Increasing evidence suggested that modest and sustained weight loss improved glycemic control in overweight and obese individuals with T2DM [3]. Furthermore, recent studies reported that intentional weight losses by low-calorie diets, usually $>15 \mathrm{~kg}$, could reverse T2DM into a nondiabetic state $[5,42]$. Based on the current studies, our study concluded that more extreme dietary energy restriction with 
TABLE 2: Side effects.

\begin{tabular}{|c|c|c|}
\hline Study ID & VLED & Control \\
\hline Carter 2016 & \multicolumn{2}{|c|}{$\begin{array}{l}\text { Hypoglycemia }(<4 \mathrm{mmol} / \mathrm{l}) \text { only occurred in insulin-controlled participants }(n=6) \text {, with no } \\
\text { difference between treatment groups }\end{array}$} \\
\hline Carter 2018 & $\begin{array}{l}\text { Hypoglycemia }(n=2) \\
\text { Hyperglycemia }(n=3) \\
\text { Headache }(n=2)\end{array}$ & $\begin{array}{l}\text { Hypoglycemia }(n=6) \\
\text { Hyperglycemia }(n=7)\end{array}$ \\
\hline Paisey 1995 & Severe hypoglycemic attack $(n=1)$ & $\begin{array}{l}\text { Myocardial infarction } \\
\qquad(n=1)\end{array}$ \\
\hline Paisey 1998 & $\begin{array}{l}\text { Nonfatal myocardial infarction }(n=1) \\
\text { Severe hypoglycemic attack }(n=1)\end{array}$ & $\begin{array}{l}\text { Nonfatal myocardial } \\
\text { infarction }(n=1)\end{array}$ \\
\hline Paisey 2002 & $\begin{array}{l}\text { Nonfatal myocardial infarction }(n=1) \\
\text { Telogen effluvium }(n=6 \text {, which recovered within } 2 \text { years of stopping VLEDs in five) }\end{array}$ & $\begin{array}{l}\text { Primary biliary cirrhosis } \\
\qquad(n=1) \\
\text { Nonfatal myocardial } \\
\text { infarction }(n=1)\end{array}$ \\
\hline Wing 1991 & $\begin{array}{l}\text { Coldness, constipation, dry skin, diarrhea, dizziness, vomiting, or weakness-commo } \\
\text { side effects of VLEDs. There were no significant differences over time in any of these sy } \\
\text { significant difference between subjects in the LED and VLED groups. However, uric a } \\
\text { significantly in the VLED group }\end{array}$ & $\begin{array}{l}\text { nly reported } \\
\text { mptoms and no } \\
\text { cid increased }\end{array}$ \\
\hline Wing 1994 & $\begin{array}{l}\text { Common side effects included cold intolerance, constipation, and hair loss, which all resolved when } \\
\text { the VLED was terminated }\end{array}$ & Unclear \\
\hline $\begin{array}{l}\text { Andorson } \\
1994\end{array}$ & $\begin{array}{c}\text { Frequently reported side effects during the weight loss phase included constipation (56 } \\
\text { diarrhea }(31 \%) \text {, dizziness }(31 \%) \text {, fatigue }(31 \%) \text {, flu/sore throat }(13 \%) \text {, headache }(10 \%) \text {, } \\
\text { blurred vision }(10 \%) \text {, muscle cramps }(8 \%) \text {, and syncope }(5 \%) \text {. None of these sid } \\
\text { required treatment alteration. }\end{array}$ & $\begin{array}{l}\% \text { of subjects), } \\
\text { jomiting }(10 \%) \\
\text { e effects }\end{array}$ \\
\hline Li 2017 & No serious adverse effects: slight headache $(n=3)$; slight dizziness $(n=1)$ & $\begin{array}{l}\text { No serious adverse } \\
\text { effects }\end{array}$ \\
\hline
\end{tabular}

VLED: very low-energy diet; LED: low-energy diet.

VLEDs is an effective method to achieve intensive weight loss in a short term and improve glycemic control more effectively compared with LEDs and MER. This conclusion supported the recommendation of the American Diabetes Association (ADA) Standards of Medical Care in Diabetes that high-intensity diet intervention, physical activity, and behavioural therapies to achieve a $500-750 \mathrm{kcal} /$ day energy deficit and maintain $>5 \%$ weight loss should be prescribed for patients with type 2 diabetes who are overweight or obese and ready to achieve weight loss. Furthermore, previous studies showed that rapid weight loss by VLEDs is inevitably followed by weight regain [42], but recent studies with at least 1-year follow-up found that VLEDs might present a longer effect on weight maintenance $[5,43]$. Another study showed that even though weight was regained, the short-term weight loss had long-lasting benefits on glycemic control and prevention of cardiovascular effects in T2DM [44]. Our results are in line with this study. After further analysis of the effects of long-term follow-up (1-5 years), we found no obvious difference in weight loss between VLEDs and LEDs, but VLEDs still maintained better glycemic control. The lasting effects of VLEDs may be attributed to improved insulin sensitivity remaining from weight loss [45], "metabolic memory" from the treatment period [46], and "legacy effect" by lifestyle intervention [47].

It is reported that dyslipidemia, especially hypertriglyceridemia, is an independent risk factor in predicting the development of diabetes, which is partially mediated by insulin resistance and obesity [48]. Several prospective studies have demonstrated that weight loss induced decreases in pancreatic and liver TG levels in T2DM, which was associated with the recovery of insulin secretory function $[6,49]$. However, the effect of weight loss by VLEDs on the plasma TG level is rarely discussed. Our meta-analyses found that VLEDs reduced the plasma TG level in T2DM more effectively compared to LEDs and MER and had an equivalent effect with bariatric surgery, which may have potential effect on preventing the development of T2DM.

Bariatric surgery is confirmed to have superior effect in T2DM [50] and has been proposed as a first-line therapy for obese patients with T2DM [3]. Bariatric surgery can restore normal liver insulin sensitivity within days and decrease plasma glucose and TG levels within weeks [51]. In this context, some studies determined whether the effects of bariatric surgery are primarily due to negative energy balance or unique to the surgical procedure $[24,51]$. Our study shows that VLEDs are as effective as bariatric surgery (mainly RYGB) in terms of weight loss, glycemic control, insulin resistance improvement, and plasma TG level reduction. Additionally, VLEDs have lower costs and lesser adverse effects compared with bariatric surgery. Thus, VLEDs may be a considerable therapy when patients could not or would not wish to undergo surgical treatments.

VLEDs were found to be acceptable as indicated by the low dropout rate in both this and a previous study. The main reason may be that rapid weight loss increases patient's confidence, and hunger of patients after VLED intervention is more inhibited. A study shows that attrition was lower when 


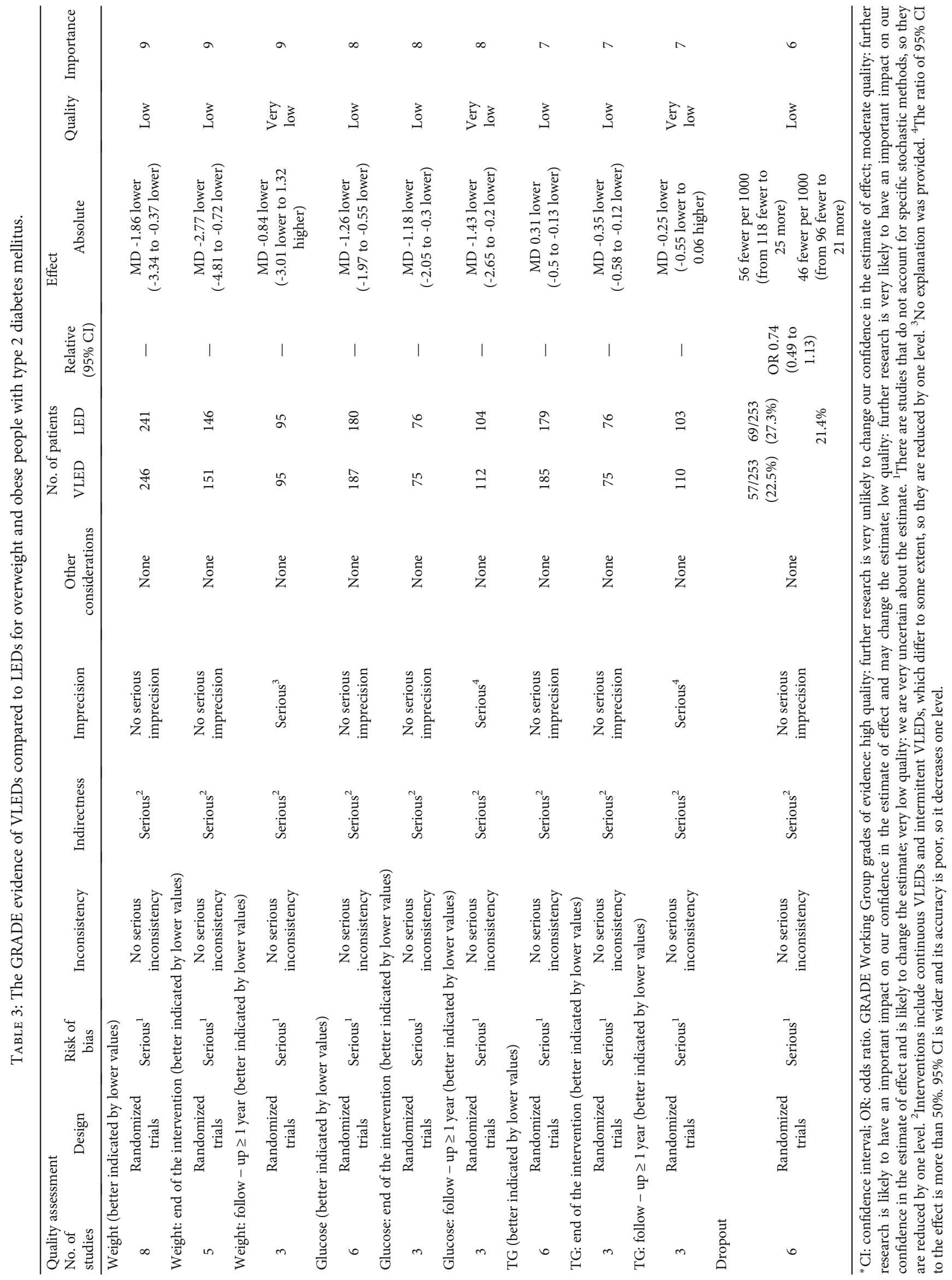




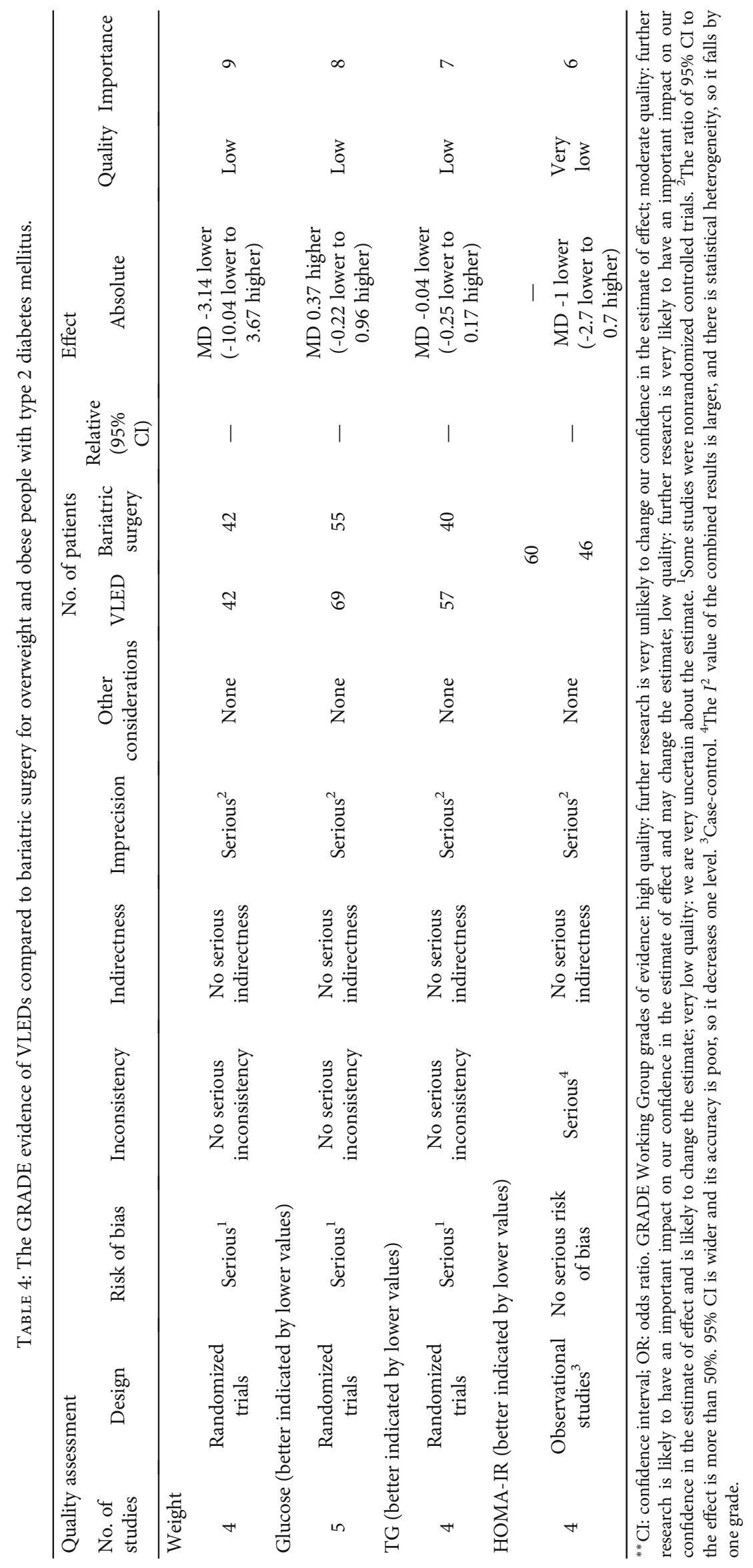




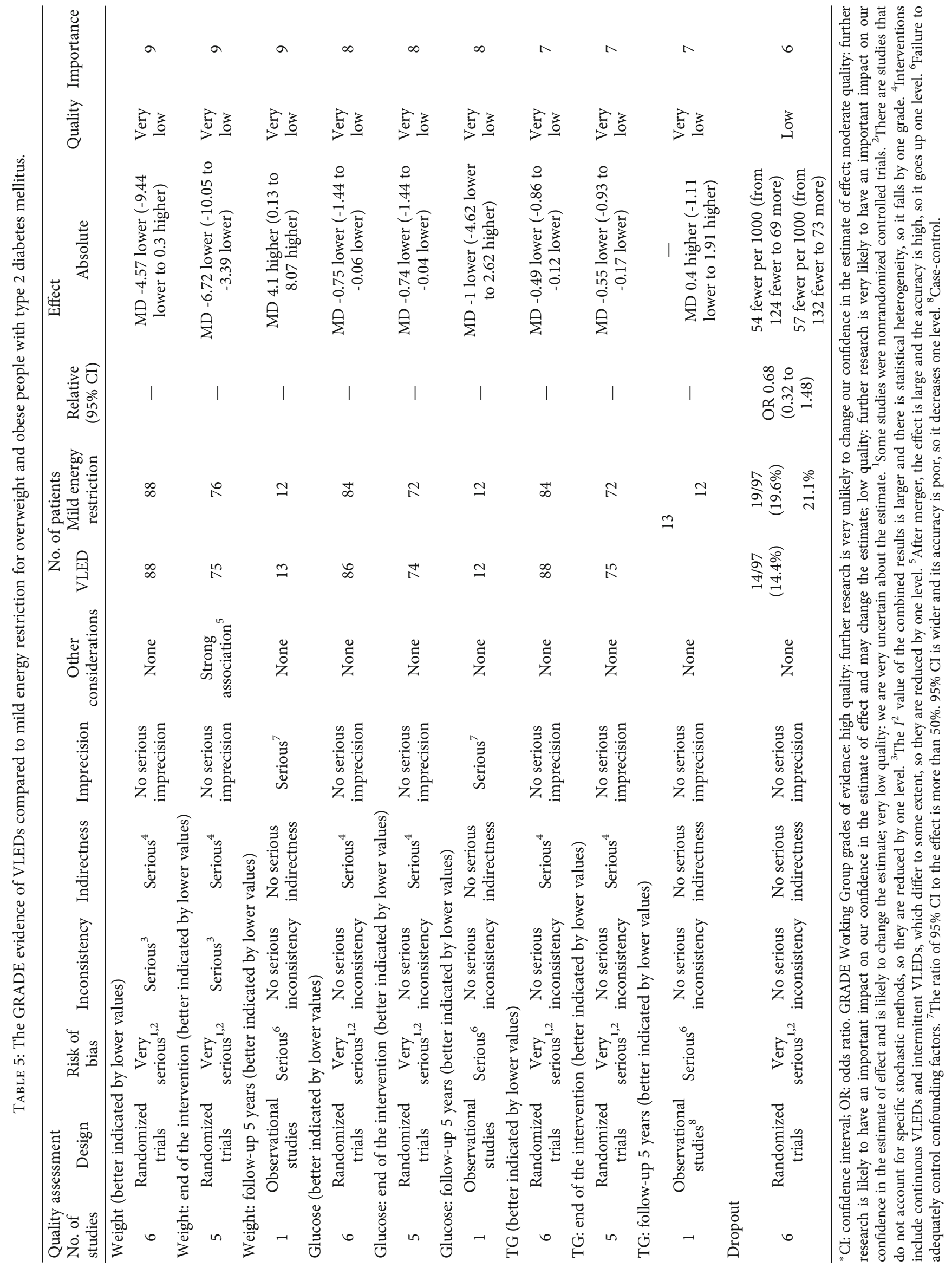


weight loss was undertaken rapidly rather than gradually, because rapid weight loss might motivate participants [52]. Moreover, ketosis suppresses appetite and increases the satiety hormone cholecystokinin, which increases the possibility that participants with rapid weight loss might have been less hungry during the weight loss phase than those following the gradual diet [53-56]. Of note, the experience of healthcare professionals involved in the trial in obesity treatment also had a significant impact on attrition.

While the short-term efficacy of VLEDs is evident and patient compliance is acceptable according to our analysis, the reports of adverse reactions in the studies are incomplete, limiting the use of this method.

In a previous systematic review, Rehackova et al. [19] revealed that VLEDs led to considerable weight loss and blood glucose control via small sample or qualitative studies. However, evidence on the long-term efficacy of VLEDs with regard to weight loss in individuals with T2DM is lacking. Our study has expanded the sample size and further analyzed the follow-up results between VLEDs and LEDs. After the follow-up (1-5 years), VLEDs present a more effective glycemic control effect, but there is no obvious difference in weight loss between VLEDs and LEDs. Some included studies [28, $30,31,37$ ] also showed that, at the end of VLED intervention, the decrease in body weight, blood glucose level, and other indicators would rebound to varying degrees. This shows that adherence to a VLED regimen is crucial in maximizing intervention effects. It has been shown that greater initial weight loss facilitates weight maintenance if followed by an effective weight loss maintenance programme [57]. Further exploring a strategy to suppress hunger after rapid weight loss and prevent weight regain of VLEDs is greatly important in the popularization of this method.

This meta-analysis provides some objective evidence for the application of VLEDs in obese individuals with T2DM, but there are still many limitations in the study. First, both non-RCTs and RCTs were combined in the meta-analyses, which increased the heterogeneity and risk of bias. Therefore, the results of this study still need to be confirmed by higherquality research. Second, some high-quality research in this field has been conducted by a small number of research groups, resulting in insufficient representation of data. Thus, more extensive studies are needed to clarify the practicability of VLEDs in different ethnic groups. Third, most included studies did not mention the use of hypoglycemic drugs in participants. When VLEDs are used to intervene with obese patients with T2DM, determination of hypoglycemic drugs is difficult. In the future, the standardized research of this area should be strengthened. Lastly, only a few included studies that recorded follow-up results, which led to insufficient convincing evidence. Moreover, the longest follow-up duration in the included studies was only 5 years, so the longterm effect of VLEDs needs further study.

\section{Conclusions}

Dietary intervention through VLEDs is more effective in rapid weight loss and glycemic control and improved lipid metabolism in overweight and obese individuals with T2DM than
LEDs and MER, although they have similar long-term effects. Moreover, VLEDs have similar efficacy and acceptability with bariatric surgery, which shows that VLEDs have considerable curative effect for remission of T2DM. However, after GRADE, it was found that all outcome indicators had low quality or base quality, so the results of this study still need to be further confirmed by high-quality research.
Abbreviations
DM: Diabetes mellitus
VLED: Very low-energy diet
LED: Low-energy diet
MER: Mild energy restriction
RYGB: Roux-en-Y gastric bypass
CI: Confidence interval
MD: $\quad$ Mean difference.

\section{Conflicts of Interest}

The authors declare that they have no competing interests.

\section{Authors' Contributions}

All authors take responsibility for the integrity of the data and the accuracy of data analysis. WJ. Liu and YN. Liu contributed to the study concept and design. YS. Huang and QY. Zheng developed the protocol design. YS. Huang, XW Fu, XQ. Zheng, CH. Xia, ZB. Zhu, and QY. Zheng carried out literature retrieval and data extraction. HS. Yang and QY. Zheng performed the statistical analysis. QY. Zheng, XQ. Zhang, and WJ. Liu performed the interpretation of data. YS. Huang and QY. Zheng are responsible for the drafting of the manuscript. HS. Yang, QY. Zheng, XQ. Zhang, WJ. Liu, and YN. Liu carried out quality assessment. WJ. Liu and YN. Liu contributed to critical revision of the manuscript. HS. Yang, WJ. Liu, and YN. Liu are responsible for technical support. All authors have read and agreed to the submission to this journal of the manuscript. Yi Shan Huang and Qiyan Zheng contributed equally to this work.

\section{Acknowledgments}

This study was supported by the National Natural Science Foundation of China (Grant Nos. 81570656 and 81774278) and the Initial Scientific Research Fund of Talent Introduction in Dongzhimen Hospital Affiliated to Beijing University of Chinese Medicine (2016TSRC).

\section{References}

[1] M. Bluher, "Obesity: global epidemiology and pathogenesis," Nature Reviews Endocrinology, vol. 15, no. 5, article 176, pp. 288-298, 2019.

[2] C. Daousi, I. F. Casson, G. V. Gill, I. A. MacFarlane, J. P. Wilding, and J. H. Pinkney, "Prevalence of obesity in type 2 diabetes in secondary care: association with cardiovascular risk factors," Postgraduate Medical Journal, vol. 82, no. 966, pp. $280-284,2006$. 
[3] American Diabetes Association, "8. Obesity management for the treatment of type 2 Diabetes:Standards of medical care in diabetes-2019," Diabetes Care, vol. 42, Supplement 1, pp. S81-S89, 2019.

[4] American Diabetes Association, "4. Lifestyle Management:Standards of medical care in diabetes-2018," Diabetes Care, vol. 41, Supplement 1, pp. S38-S50, 2018.

[5] M. E. Lean, W. S. Leslie, A. C. Barnes et al., "Primary care-led weight management for remission of type 2 diabetes (DiRECT): an open-label, cluster-randomised trial," Lancet, vol. 391, no. 10120, pp. 541-551, 2018.

[6] E. L. Lim, K. G. Hollingsworth, B. S. Aribisala, M. J. Chen, J. C. Mathers, and R. Taylor, "Reversal of type 2 diabetes: normalisation of beta cell function in association with decreased pancreas and liver triacylglycerol," Diabetologia, vol. 54, no. 10, pp. 2506-2514, 2011.

[7] M. L. Gow, L. A. Baur, N. A. Johnson, C. T. Cowell, and S. P. Garnett, "Reversal of type 2 diabetes in youth who adhere to a very-low-energy diet: a pilot study," Diabetologia, vol. 60, no. 3, pp. 406-415, 2017.

[8] H. M. Parretti, S. A. Jebb, D. J. Johns, A. L. Lewis, A. M. Christian-Brown, and P. Aveyard, "Clinical effectiveness of very-low-energy diets in the management of weight loss: a systematic review and meta-analysis of randomized controlled trials," Obesity Reviews, vol. 17, no. 3, pp. 225-234, 2016.

[9] R. L. Atkinson, W. H. Dietz, J. P. Foreyt et al., "Very lowcalorie diets. National Task Force on the Prevention and Treatment of Obesity, National Institutes of Health," JAMA, vol. 270, no. 8, pp. 967-974, 1993.

[10] S. Andela, T. L. Burrows, L. A. Baur, D. H. Coyle, C. E. Collins, and M. L. Gow, "Efficacy of very low-energy diet programs for weight loss: a systematic review with meta-analysis of intervention studies in children and adolescents with obesity," Obesity Reviews, vol. 20, no. 6, pp. 871-882, 2019.

[11] P. Sumithran, L. A. Prendergast, E. Delbridge et al., "Longterm persistence of hormonal adaptations to weight loss," New England Journal of Medicine, vol. 365, no. 17, pp. 15971604, 2011.

[12] A. E. Rothberg, L. N. McEwen, A. T. Kraftson, C. E. Fowler, and W. H. Herman, "Very-low-energy diet for type 2 diabetes: an underutilized therapy?," Journal of Diabetes and its Complications, vol. 28, no. 4, pp. 506-510, 2014.

[13] L. Rehackova, V. Araujo-Soares, A. J. Adamson, S. Steven, R. Taylor, and F. F. Sniehotta, "Acceptability of a very-lowenergy diet in type 2 diabetes: patient experiences and behaviour regulation," Diabetic Medicine, vol. 34, no. 11, pp. 15541567, 2017.

[14] L. Rehackova, V. Araujo-Soares, S. Steven, A. J. Adamson, R. Taylor, and F. F. Sniehotta, "Behaviour change during dietary type 2 diabetes remission: a longitudinal qualitative evaluation of an intervention using a very low energy diet," Diabetic Medicine, pp. 1-10, 2019.

[15] L. Harris, A. McGarty, L. Hutchison, L. Ells, and C. Hankey, "Short-term intermittent energy restriction interventions for weight management: a systematic review and meta-analysis," Obesity Reviews, vol. 19, no. 1, pp. 1-13, 2018.

[16] A. R. Barnosky, K. K. Hoddy, T. G. Unterman, and K. A. Varady, "Intermittent fasting vs daily calorie restriction for type 2 diabetes prevention: a review of human findings," Translational Research, vol. 164, no. 4, pp. 302-311, 2014.
[17] N. M. Astbury, P. Aveyard, A. Nickless et al., "Doctor Referral of Overweight People to Low Energy total diet replacement Treatment (DROPLET): pragmatic randomised controlled trial," BMJ, vol. 362, article k3760, 2018.

[18] D. E. Kloecker, F. Zaccardi, E. Baldry, M. J. Davies, K. Khunti, and D. R. Webb, "Efficacy of low- and very-low-energy diets in people with type 2 diabetes mellitus: a systematic review and meta-analysis of interventional studies," Diabetes Obesity and Metabolism, vol. 21, no. 7, pp. 1695-1705, 2019.

[19] L. Rehackova, B. Arnott, V. Araujo-Soares, A. A. Adamson, R. Taylor, and F. F. Sniehotta, "Efficacy and acceptability of very low energy diets in overweight and obese people with type 2 diabetes mellitus: a systematic review with meta-analyses," Diabetic Medicine, vol. 33, no. 5, pp. 580-591, 2016.

[20] J. P. Higgins and S. Green, Cochrane Handbook for Systematic Reviews of Interventions, John Wiley \& Sons, Chichester (UK), 2011.

[21] J. A. C. Sterne, M. A. Hernán, B. C. Reeves et al., "ROBINS-I: a tool for assessing risk of bias in non-randomised studies of interventions," BMJ, vol. 355, article i4919, 2016.

[22] G. H. Guyatt, A. D. Oxman, G. E. Vist et al., "GRADE: an emerging consensus on rating quality of evidence and strength of recommendations," BMJ, vol. 336, no. 7650, pp. 924-926, 2008.

[23] S. Green, Cochrane Handbook for Systematic Reviews of Interventions. Version 5.1.0, The Cochrane Collaboration, United Kingdom, 2011.

[24] C. Jackness, W. Karmally, G. Febres et al., "Very low-calorie diet mimics the early beneficial effect of Roux-en-Y gastric bypass on insulin sensitivity and $\beta$-Cell function in type 2 diabetic patients," Diabetes, vol. 62, no. 9, pp. 3027-3032, 2013.

[25] J. W. Anderson, V. Brinkman-Kaplan, C. C. Hamilton, J. E. B. Logan, R. W. Collins, and N. J. Gustafson, "Food-containing hypocaloric diets are as effective as liquid-supplement diets for obese individuals with NIDDM," Diabetes Care, vol. 17, no. 6, pp. 602-604, 1994.

[26] S. Carter, P. M. Clifton, and J. B. Keogh, "The effects of intermittent compared to continuous energy restriction on glycaemic control in type 2 diabetes; a pragmatic pilot trial," Diabetes Research and Clinical Practice, vol. 122, pp. 106-112, 2016.

[27] S. Carter, P. M. Clifton, and J. B. Keogh, "Effect of intermittent compared with continuous energy restricted diet on glycemic control in patients with type 2 diabetes: a randomized noninferiority trial," JAMA Network Open, vol. 1, no. 3, article e180756, 2018.

[28] S. Carter, P. M. Clifton, and J. B. Keogh, "The effect of intermittent compared with continuous energy restriction on glycaemic control in patients with type 2 diabetes: 24-month follow-up of a randomised noninferiority trial," Diabetes Research and Clinical Practice, vol. 151, pp. 11-19, 2019.

[29] J. Harvey, R. R. Wing, and M. Mullen, "Effects on food cravings of a very low calorie diet or a balanced, low calorie diet," Appetite, vol. 21, no. 2, pp. 105-115, 1993.

[30] R. R. Wing, M. D. Marcus, R. Salata, L. H. Epstein, S. Miaskiewicz, and E. H. Blair, "Effects of a very-low-calorie diet on long-term glycemic control in obese type 2 diabetic subjects," Archives of Internal Medicine, vol. 151, no. 7, pp. 1334-1340, 1991.

[31] R. R. Wing, E. Blair, M. Marcus, L. H. Epstein, and J. Harvey, "Year-long weight loss treatment for obese patients with type II diabetes: does including an intermittent very-low-calorie 
diet improve outcome?," American Journal of Medicine, vol. 97, no. 4, pp. 354-362, 1994.

[32] M. A. Lips, H. Pijl, J. B. van Klinken et al., "Roux-en-Y gastric bypass and calorie restriction induce comparable timedependent effects on thyroid hormone function tests in obese female subjects," European Journal of Endocrinology, vol. 169, no. 3, pp. 339-347, 2013.

[33] L. Plum, L. Ahmed, G. Febres et al., "Comparison of glucostatic parameters after hypocaloric diet or bariatric surgery and equivalent weight loss," Obesity, vol. 19, no. 11, pp. 2149-2157, 2011.

[34] A. Cinkajzlová, M. Mráz, Z. Lacinová et al., “Angiopoietin-like protein 3 and 4 in obesity, type 2 diabetes mellitus, and malnutrition: the effect of weight reduction and realimentation," Nutrition \& Diabetes, vol. 8, no. 1, p. 21, 2018.

[35] S. Steven, K. G. Hollingsworth, P. K. Small et al., "Calorie restriction and not glucagon-like peptide-1 explains the acute improvement in glucose control after gastric bypass in type 2 diabetes," Diabetic Medicine, vol. 33, no. 12, pp. 1723-1731, 2016.

[36] R. B. Paisey, P. Harvey, S. Rice et al., "An intensive weight loss programme in established type 2 diabetes and controls: effects on weight and atherosclerosis risk factors at 1 year," Diabetic Medicine, vol. 15, no. 1, pp. 73-79, 1998.

[37] R. B. Paisey, J. Frost, P. Harvey et al., "Five year results of a prospective very low calorie diet or conventional weight loss programme in type 2 diabetes," Journal of Human Nutrition and Dietetics, vol. 15, no. 2, pp. 121-127, 2002.

[38] R. Paisey, P. Harvey, S. Rice et al., "Short-term results of an open trial of very low calorie diet or intensive conventional diet in Type 2 diabetes," Practical Diabetes International, vol. 12, no. 6, pp. 263-267, 1995.

[39] C. Li, B. Sadraie, N. Steckhan et al., "Effects of a one-week fasting therapy in patients with type-2 diabetes mellitus and metabolic syndrome - a randomized controlled explorative study," Experimental and Clinical Endocrinology \& Diabetes, vol. 125, no. 9, pp. 618-624, 2017.

[40] K. V. Williams, M. L. Mullen, D. E. Kelley, and R. R. Wing, "The effect of short periods of caloric restriction on weight loss and glycemic control in type 2 diabetes," Diabetes Care, vol. 21, no. 1, pp. 2-8, 1998.

[41] M. Laakso, M. Uusitupa, J. Takala, H. Majander, T. Reijonen, and I. Penttila, "Effects of hypocaloric diet and insulin therapy on metabolic control and mechanisms of hyperglycemia in obese non-insulin-dependent diabetic subjects," Metabolism, vol. 37, no. 11, pp. 1092-1100, 1988.

[42] M. E. J. Lean, "Low-calorie diets in the management of type 2 diabetes mellitus," Nature Reviews Endocrinology, vol. 15, no. 5, article 186, pp. 251-252, 2019.

[43] M. J. Franz, J. J. VanWormer, A. L. Crain et al., "Weight-Loss Outcomes: A Systematic Review and Meta-Analysis of Weight-Loss Clinical Trials with a Minimum 1-Year FollowUp," Journal of the American Dietetic Association, vol. 107, no. 10, pp. 1755-1767, 2007.

[44] A. C. Feldstein, G. A. Nichols, D. H. Smith et al., "Weight change in diabetes and glycemic and blood pressure control," Diabetes Care, vol. 31, no. 10, pp. 1960-1965, 2008.

[45] L. Aucott, A. Poobalan, W. C. S. Smith et al., "Weight loss in obese diabetic and non-diabetic individuals and long-term diabetes outcomes-a systematic review," Diabetes Obesity and Metabolism, vol. 6, no. 2, pp. 85-94, 2004.
[46] D. LeRoith, V. Fonseca, and A. Vinik, "Metabolic memory in diabetes-focus on insulin," Diabetes/Metabolism Research and Reviews, vol. 21, no. 2, pp. 85-90, 2005.

[47] J. Tuomilehto, P. Schwarz, and J. Lindstrom, "Long-term benefits from lifestyle interventions for type 2 diabetes prevention: time to expand the efforts," Diabetes Care, vol. 34, Supplement 2, pp. S210-S214, 2011.

[48] R. B. D’Agostino Jr., R. F. Hamman, A. J. Karter, L. Mykkanen, L. E. Wagenknecht, and S. M. Haffner, "Cardiovascular disease risk factors predict the development of type 2 diabetes: the insulin resistance atherosclerosis study," Diabetes Care, vol. 27, no. 9, pp. 2234-2240, 2004.

[49] S. Steven, K. G. Hollingsworth, P. K. Small et al., "Weight loss decreases excess pancreatic triacylglycerol specifically in type 2 diabetes," Diabetes Care, vol. 39, no. 1, pp. 158-165, 2016.

[50] F. Rubino, D. M. Nathan, R. H. Eckel et al., "Metabolic surgery in the treatment algorithm for type 2 diabetes: a joint statement by International Diabetes Organizations," Obesity Surgery, vol. 27, no. 1, pp. 2-21, 2017.

[51] R. Taylor, "Pathogenesis of type 2 diabetes: tracing the reverse route from cure to cause," Diabetologia, vol. 51, no. 10, pp. 1781-1789, 2008.

[52] K. Purcell, P. Sumithran, L. A. Prendergast, C. J. Bouniu, E. Delbridge, and J. Proietto, "The effect of rate of weight loss on long-term weight management: a randomised controlled trial," The Lancet Diabetes \& Endocrinology, vol. 2, no. 12, pp. 954-962, 2014.

[53] G. L. Pawan and S. J. Semple, "Effect of 3-hydroxybutyrate in obese subjects on very-low-energy diets and during therapeutic starvation," Lancet, vol. 1, no. 8314-5, pp. 15-17, 1983.

[54] F. J. McClernon, W. S. Yancy, J. A. Eberstein, R. C. Atkins, and E. C. Westman, "The effects of a low-carbohydrate ketogenic diet and a low-fat diet on mood, hunger, and other selfreported symptoms," Obesity, vol. 15, no. 1, pp. 182-187, 2007.

[55] A. M. Johnstone, G. W. Horgan, S. D. Murison, D. M. Bremner, and G. E. Lobley, "Effects of a high-protein ketogenic diet on hunger, appetite, and weight loss in obese men feeding ad libitum," American Journal of Clinical Nutrition, vol. 87, no. 1, pp. 44-55, 2008.

[56] S. Chearskul, E. Delbridge, A. Shulkes, J. Proietto, and A. Kriketos, "Effect of weight loss and ketosis on postprandial cholecystokinin and free fatty acid concentrations," American Journal of Clinical Nutrition, vol. 87, no. 5, pp. 1238-1246, 2008.

[57] A. Astrup and S. Rossner, "Lessons from obesity management programmes: greater initial weight loss improves long-term maintenance," Obesity Reviews, vol. 1, no. 1, pp. 17-19, 2000. 